Velilla Gil, J., Guallart Moreno, C., Laguna Marín-Yaseli, M. (2021). Materiales educativos para trabajar conceptos sobre desarrollo sostenible en las aulas de educación secundaria. GeoFocus (Artículos), Revista Internacional de Ciencia y Tecnología de la Información Geográfica, 27, 55-93. http://dx.doi.org/10.21138/GF.676

\title{
MATERIALES EDUCATIVOS PARA TRABAJAR CONCEPTOS SOBRE DESARROLLO SOSTENIBLE EN LAS AULAS DE EDUCACIÓN SECUNDARIA
}

\author{
${ }^{1 \mathrm{a} J A V I E R ~ V E L I L L A ~ G I L, ~}{ }^{2 \mathrm{~b}}$ CARLOS GUALLART MORENO (D), ${ }^{3 \mathrm{c}}$ MARÍA \\ LAGUNA MARÍN-YASELI \\ ${ }^{1}$ IES El Portillo \\ Calle Juan XXIII, 3, 50010 Zaragoza, España \\ ${ }^{2}$ Colegio Santa María del Pilar \\ Paseo Reyes de Aragón, 5, 50012 Zaragoza, España \\ ${ }^{3}$ Colegio El Salvador \\ Calle Padre Arrupe, 13, 50009 Zaragoza, España \\ ajvelillagil@gmail.com, ${ }^{\mathrm{b}}$ cguallart@gmail.com, ${ }^{{ }^{c} \text { mlaguna@jesuitaszaragoza.es }}$
}

\section{RESUMEN}

Los materiales educativos que presentamos han sido elaborados por los autores de este artículo con los objetivos de desarrollar en las aulas de Educación Secundaria procesos de enseñanza-aprendizaje competenciales, que hagan de los alumnos ciudadanos capaces de comprender el contexto en el que se desarrolla su vida, introducir en los currículos aprendizajes sobre desarrollo sostenible, y utilizar en esos procesos herramientas de los Sistemas de Información Geográfica (SIG) para avanzar en el logro de los objetivos didácticos planteados. Para ello, se han seleccionado como contenidos relevantes: los procesos de despoblación en Aragón, la problemática del mundo rural (plasmado en los materiales "paisaje, patrimonio cultural y despoblación") y el cambio climático y sus repercusiones. Se presentarán los materiales describiendo sus contenidos y sus herramientas de aprendizaje, y enumerando las fuentes de los datos con los que se han elaborado, para posteriormente mostrar los resultados provisionales obtenidos de su experimentación en las aulas, insistiendo en las circunstancias en las que esta se realizó, y concluyendo con la necesidad de una experimentación más consistente y objetiva.

Palabras clave: sostenible; despoblación; rural; cambio climático; patrimonio; educación; competencias, SIG.

\section{EDUCATIONAL MATERIALS TO WORK ON SUSTAINABLE DEVELOPMENT CONCEPTS IN SECONDARY EDUCATION CLASSROOMS.}

\section{ABSTRACT}

We develop and show some educational materials with the main objective of developing competency teaching-learning processes in high school, making students citizens capable of understanding the context in which their lives take place. We also introduce learning about 


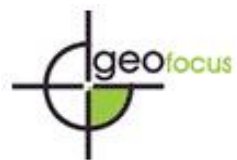

Velilla Gil, J., Guallart Moreno, C., Laguna Marín-Yaseli, M. (2021). Materiales educativos para trabajar conceptos sobre desarrollo sostenible en las aulas de educación secundaria. GeoFocus (Artículos), Revista Internacional de Ciencia y Tecnología de la Información Geográfica, 27, 55-93. http://dx.doi.org/10.21138/GF.676

sustainable development in the curricula, and the use of Geographic Information Systems (GIS) in such processes, in order to advance in the achievement of the didactic objective. In doing so, we have identified the following relevant contents: the depopulation processes in the Aragón region, the problems of the rural areas (available at "landscape, cultural heritage and depopulation"), and climate change and some related effects. The materials will be presented, describing their contents and learning tools in detail, and the data with which such materials have been prepared. Finally, we show the preliminary results found in a field-experiment in high-school classrooms, focusing on the circumstances in which this experiment was carried out. The main conclusion of his study is the need for a more consistent and objective experimentation process.

Keywords: Sustainable; depopulation; rural; climate change; inheritance; education; skills, GIS.

\section{Introducción}

El objetivo de este artículo es presentar y analizar la calidad de unos materiales educativos que pretenden introducir en las aulas de Educación Secundaria la idea de desarrollo sostenible $\mathrm{y}$, además, hacerlo con herramientas SIG que, utilizadas para llevar a cabo unas estrategias didácticas, permiten realizar aprendizajes orientados a la adquisición de competencias (De Lázaro y González, 2005).

Para conseguir esos objetivos, se han planteado tres líneas de actuación, que enumeramos a continuación y analizaremos detalladamente en el apartado "2. Metodología para la elaboración de los materiales":

1. El establecimiento de un modelo y unas estrategias didácticas (Marqués y Álvarez, 2014).

2. El uso con fines educativos de herramientas SIG (Kerski, 2011).

3. La formulación de temas y contenidos actuales que resulten relevantes para la articulación de un currículo educativo que tenga como objetivos aprendizajes en competencias y la creación de conocimiento, así como generar una educación para el desarrollo sostenible (De Miguel, 2012).

El conjunto de materiales se organiza en tres bloques temáticos, que se corresponden con tres iniciativas diferentes que tienen en común los objetivos y las herramientas didácticas con las que se realizaron:

1. En noviembre de 2018, aprovechando la invitación del Grupo de Didáctica de la Asociación Española de Geografía (AGE), para plantear líneas de trabajo en el marco del acuerdo entre la AGE y ESRI-España firmado en julio de ese mismo año, los autores de este artículo comenzaron la elaboración del conjunto de materiales sobre los procesos de despoblación en Aragón.

2. Casi un año después, en septiembre de 2019, comenzó a desarrollarse el proyecto Paisaje, patrimonio cultural y despoblación, seleccionado para su ejecución en la "Primera Convocatoria de Estancias de Investigación y Proyectos Gonzalo M. Borrás Gualis 2019", patrocinada por la asociación de municipios "Territorio Mudéjar" (https://www.territoriomudejar.es/patrimonio-mudejar-y-aprendizaje-el-materialpedagogico-conocer-el-patrimonio-para-valorarlo-e-idear-modelos-de-desarrollorural/) para el estudio y diseño de implantación de proyectos vinculados con los 


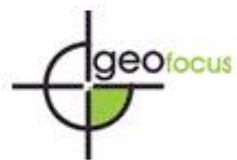

Velilla Gil, J., Guallart Moreno, C., Laguna Marín-Yaseli, M. (2021). Materiales educativos para trabajar conceptos sobre desarrollo sostenible en las aulas de educación secundaria. GeoFocus (Artículos), Revista Internacional de Ciencia y Tecnología de la Información Geográfica, 27, 55-93. http://dx.doi.org/10.21138/GF.676

recursos culturales y patrimoniales de los municipios de la provincia de Zaragoza, pertenecientes a dicha asociación. En él participaron, además de los tres autores de este artículo, otros cuatro profesores e investigadores: Ollero Ojeda, A., Cuartero Latorre, N., Ferraz Gracia, F., y Rodrigo Garza, B.

3. A la par, se fue planteando la necesidad de dar mayor relevancia educativa a los contenidos sobre el cambio climático y sus repercusiones, por lo que fue elaborada la cartografía correspondiente, adaptándola a los cambios de modelo que ha ido realizando el Panel Intergubernamental de Expertos [IPCC] (https://www.ipcc.ch/). Los objetivos de este grupo de contenidos han sido favorecer aprendizajes sobre el cambio climático y sus repercusiones en la población, y que estos tuviesen un carácter competencial.

Conforme se han ido elaborando estos materiales, los autores fueron experimentándolos con sus alumnos con el objeto de poder corregir algunos errores de funcionamiento y mejorar sus resultados formativos. Posteriormente, se llevó a cabo un testeado de los mismos que, por diversas circunstancias (premura en el tiempo, circunstancias asociadas al calendario escolar, la irrupción de la COVID-19, etc.) no se pudo plantear de forma sistemática y exhaustiva y quedó reducido a la utilización en las aulas de algunas herramientas y contenidos considerados significativos por los autores y por otros profesores, miembros de un grupo de trabajo reconocido por la administración educativa aragonesa, que durante los últimos cinco años ha estado investigando sobre la utilidad de los SIG para llevar a cabo procesos de enseñanzaaprendizaje competenciales, que se ofreció para realizarlo. Esta evaluación se ha basado en la medición de la adquisición, por parte de los alumnos, de las competencias que se plantean como objetivos para los materiales y que se especifican en el siguiente apartado. Una nueva experimentación, más objetiva y consistente, ha quedado pendiente para cuando el contexto educativo no se vea sometido a las consecuencias que la COVID-19 origina en la vida escolar.

\section{Metodología para la elaboración de los materiales}

\subsection{Modelo y estrategias didácticas:}

\subsubsection{El modelo didáctico.}

El punto de partida ha sido el modelo del denominado currículo bimodal (Marqués y Álvarez, 2014), que está teniendo muy buenos resultados (Pérez Gómez, 2012), tanto en la calidad de los aprendizajes como en los resultados académicos obtenidos por los alumnos. Este modelo plantea como objetivo la actualización de las estrategias didácticas para adecuarlas al contexto de la sociedad de la información, buscando el éxito, medido por la calidad y el valor de los aprendizajes realizados.

Para ello, diferencia dos componentes básicos en los aprendizajes:

1. Los conceptos o conocimientos fundamentales que permiten leer, comprender, analizar, evaluar, etc. los contenidos con los que, en cada materia y, también, de forma transversal se van a realizar las tareas de aprendizaje. Estos conceptos deben ser comprendidos y memorizados hasta alcanzar la evidencia para poder realizar tareas de aprendizaje.

2. Tareas con las que se genera la adquisición de destrezas a través de la realización de aprendizajes eficientes con herramientas adecuadas. Estas destrezas se asocian con saber hacer, saber resolver, saber aprender. 


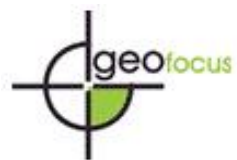

Velilla Gil, J., Guallart Moreno, C., Laguna Marín-Yaseli, M. (2021). Materiales educativos para trabajar conceptos sobre desarrollo sostenible en las aulas de educación secundaria. GeoFocus (Artículos), Revista Internacional de Ciencia y Tecnología de la Información Geográfica, 27, 55-93. http://dx.doi.org/10.21138/GF.676

A partir de estas ideas esenciales, los materiales educativos que se presentan aquí adoptan dos formatos que se corresponden a sus dos funciones:

1. Aquellos en los que se identifican y explican los conceptos básicos y esenciales. Es importante señalar que, como indicábamos antes, el aparato conceptual con el que se trabaja en cada materia, de forma singular en Geografía, no tiene por qué ser exclusivo de la misma, sino que una parte importante de él es transversal a varias o a todas ellas. También que, en ese conjunto conceptual, se diferencian aquellos conceptos que resultan esenciales para avanzar en los itinerarios formativos, de aquellos otros que se orientan a profundizar en esos itinerarios. Los que resultan esenciales son los que todos los alumnos, con una estrategia didáctica u otra, deben aprender.

2. Un conjunto de actividades "por proyectos" encaminadas a la construcción del conocimiento y a la adquisición de competencias o destrezas por quien las realiza (Larmer y Mergendoller, 2010). En palabras de Marqués y Álvarez, 2014, p. 153:

Consideramos actividades prácticas todas las que suponen la realización de una tarea de aplicación de conocimiento o de creación, como, por ejemplo: resolver problemas, analizar frases o procesos, evaluar situaciones o materiales, planificar y desarrollar proyectos, realizar síntesis y crear. El enfoque del currículo bimodal prescribe que los alumnos siempre podrán realizar estas actividades prácticas con apoyo de su «memoria auxiliar», es decir, consultando sus apuntes, libros e Internet. El profesor decidirá en cada caso qué fuentes de información se pueden utilizar. El objetivo es que los estudiantes se acostumbren a trabajar contando con estos apoyos (apuntes, libros, Internet y otras herramientas TIC), que estarán a su disposición cuando sean adultos.

Siguiendo esta estrategia, las tareas se plantean en nuestros materiales en una "barra de herramientas" en la que una de ellas, denominada "Indicaciones", tiene dos apartados principales: "explicaciones" y "tareas". En el primero se señalan y explican esos conceptos necesarios para realizar las "tareas", que en el segundo apartado se describen como itinerarios para la resolución de problemas, indicando los pasos necesarios para ir avanzando y las herramientas con las que hacerlo. De esta forma, esas descripciones y esas indicaciones hacen que la destreza en el manejo de la herramienta no sea un obstáculo para la obtención de los aprendizajes que se pretenden.

Se trata, en definitiva, de que la incomprensión de alguno de esos conceptos básicos no impida el inicio de tareas y, por el contrario, que la realización de esas tareas refuerce la construcción del conocimiento y la comprensión de los pilares conceptuales en los que se sustenta.

\subsubsection{La educación como formación en competencias}

La educación es entendida por nosotros como un proceso de adquisición de destrezas o capacidades, entre las que se encuentra la espacial, una de las inteligencias múltiples (Gardner, 1993), y que posibilita a los ciudadanos para que puedan hacer frente de forma eficaz a los problemas que les plantea el contexto en el que viven. Como señalan Ballester y Sánchez (2010):

Por competencia entendemos los saberes que un alumno o conjunto de alumnos ponen en acción para dar respuestas pensadas, sentidas, efectivas y actualizadas 


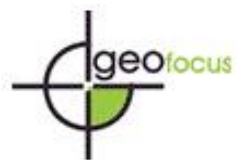

Velilla Gil, J., Guallart Moreno, C., Laguna Marín-Yaseli, M. (2021). Materiales educativos para trabajar conceptos sobre desarrollo sostenible en las aulas de educación secundaria. GeoFocus (Artículos), Revista Internacional de Ciencia y Tecnología de la Información Geográfica, 27, 55-93. http://dx.doi.org/10.21138/GF.676

a las demandas de un entorno complejo, cambiante y contradictorio, en ocasiones, en el que inscriben su vida (p.19).

Esta forma de entender la educación comenzó a extenderse definitivamente en los países europeos a partir del planteamiento en el campo de las políticas educativas de la Agenda de Lisboa (Consejo Europeo de Lisboa, 23 y 24 de marzo de 2000), que cinco años después se concretó en la Propuesta de Recomendación del Parlamento Europeo y del Consejo sobre las competencias clave para el aprendizaje permanente (COM, 2005, 548 final, de 10 de noviembre de 2005), donde se define competencia como una combinación de conocimientos, capacidades y actitudes adecuados para una determinada situación. Las "competencias clave" son aquellas en las que se sustentan la realización personal, la inclusión social, la ciudadanía activa y el empleo (p. 3). Todo ello en el contexto de los cambios introducidos por la irrupción de la sociedad del conocimiento (Castells, 2001).

Este modelo educativo debe pues, girar en torno a las interacciones entre ciudadanos y el contexto en el que desarrollan sus vidas, que incluye las relaciones personales, sociales, laborales, políticas, etc. La adopción de estos objetivos supone un cambio en el sistema educativo que, en palabras de la citada propuesta, pone de manifiesto el cambio del enfoque aplicado, que ha pasado de la transmisión de conocimientos al desarrollo de competencias transferibles que preparen a los jóvenes para la vida adulta y el aprendizaje complementario (p.5). Lo que lleva consigo una transición desde modelos educativos en los que se transmitía a los estudiantes los conceptos y herramientas que constituyen el armazón epistemológico de las materias estudiadas, con el objeto de avanzar en el conocimiento de las mismas, a otro en el que, a partir de los conceptos y herramientas de las diferentes materias, se pretende desarrollar aprendizajes que capaciten para vivir e interactuar de forma responsable con y en ese contexto. La formulación de las competencias "clave" o "básicas" (comunicación lingüística, competencia matemática y competencias básicas en ciencia y tecnología, competencia digital, aprender a aprender, competencias sociales y cívicas, sentido de iniciativa y espíritu emprendedor y competencia y expresiones culturales) se realiza en la Orden ECD/65/2015, de 21 de enero, por la que se describen las relaciones entre las competencias, los contenidos y los criterios de evaluación de Educación Primaria, Educación Secundaria Obligatoria y Bachillerato. La concreción de esas competencias para nuestros materiales educativos es:

1. Destrezas específicas en los aprendizajes geográficos y sus estándares de aprendizaje:

A. Adquirir competencias para la localización espacial. Estándares de aprendizaje: utilizando los puntos cardinales, las unidades de relieve, la red hidrológica, la cercanía o lejanía del mar, etc. localiza espacios y elementos geográficos.

B. Ser capaz de identificar los elementos que componen el territorio. Estándares de aprendizaje: diferencia elementos físicos y antrópicos; los localiza en el mapa y en el paisaje; identifica los diferentes tipos de elementos físicos y antrópicos.

C. Ser competente para identificar las interrelaciones entre elementos territoriales. Estándares de aprendizaje: a partir de las coincidencias o las diferencias en la distribución en el espacio de diferentes tipos de información, establece las relaciones que hay entre ellos.

D. Ser capaz de identificar la causalidad a partir de la comprensión de esas interrelaciones. Estándares de aprendizaje: a partir de las coincidencias o las diferencias en la distribución en el espacio de diferentes tipos de información y del conocimiento de sus respectivas características, establece las relaciones multicausales que se establecen entre ellos. 
Velilla Gil, J., Guallart Moreno, C., Laguna Marín-Yaseli, M. (2021). Materiales educativos para trabajar conceptos sobre desarrollo sostenible en las aulas de educación secundaria. GeoFocus (Artículos), Revista Internacional de Ciencia y Tecnología de la Información Geográfica, 27, 55-93. http://dx.doi.org/10.21138/GF.676

E. Desarrollar la autoestima y el empoderamiento para ser capaz de formalizar hipótesis y formular propuestas razonadas de cambio. Estándares de aprendizaje: elabora hipótesis razonables de investigación y, a partir del trabajo con información, establece argumentos o demostraciones para justificarla o modificarla; comunica sus resultados, siendo capaz de admitir sus errores y de avaluar las obtenidas por otros compañeros.

2. Destrezas generales de carácter transversal (elaboradas a partir de Binkley et al. (2012):

- Relacionadas con el pensamiento:

A. Desarrollar la creatividad y la innovación. Estándares de aprendizaje: elabora o plantea hipótesis; utiliza nuevas ideas para solucionar problemas; está interesado en las TIC como herramientas para aprender mejor.

B. Ser capaz de pensar críticamente. Estándares de aprendizaje: comprende los problemas planteados; identifica causas y consecuencias; busca soluciones a los problemas

C. Ser competente para "aprender a aprender". Estándares de aprendizaje: utiliza conceptos y herramientas de diferentes materias para resolver problemas geográficos; utiliza aprendizajes anteriores para resolver problemas.

- Relacionadas con "saber hacer":

A. Capacidad para comunicar informaciones. Estándares de aprendizaje: usa diferentes formatos (texto, expresión oral, imagen, vídeo, mapas, etc.) para comunicar; al comunicarse, utiliza una cantidad suficiente de información; se comunica de una forma lógica y ordenada; se comunica utilizando estrategias de empatía.

B. Competencia para colaborar y trabajar en equipo. Estándares de aprendizaje: colabora con sus compañeros cuando trabaja en equipo; evalúa críticamente sus planteamientos y los de sus compañeros; identifica y comprende su posición en el grupo.

- En el manejo de herramientas de trabajo.

A. Capacidad para tratar la información. Estándares de aprendizaje: identifica fuentes de información; selecciona información objetiva, pertinente y relevante para el tema en el que trabaja; trata la información de forma adecuada para representar lo que desea; conoce diferentes formatos en los que se puede presentar la información; evalúa las ventajas e inconvenientes de los diferentes formatos en los que se puede presentar la información.

B. Capacidad para utilizar las TIC. Estándares de aprendizaje: maneja adecuadamente editores de texto, de imágenes y de vídeo, así como hojas de cálculo; utiliza herramientas TIC para resolver problemas; diferencia redes de comunicación y fuentes de información.

- Destrezas ciudadanas:

A. Competencia para asumir responsabilidades en la vida y los estudios. Estándares de aprendizaje: realiza las tareas encomendadas y acepta sus errores e intenta corregirlos.

B. Competencia para asumir responsabilidades en las relaciones sociales. Estándares 


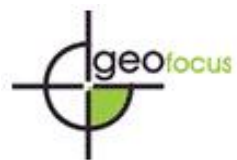

Velilla Gil, J., Guallart Moreno, C., Laguna Marín-Yaseli, M. (2021). Materiales educativos para trabajar conceptos sobre desarrollo sostenible en las aulas de educación secundaria. GeoFocus (Artículos), Revista Internacional de Ciencia y Tecnología de la Información Geográfica, 27, 55-93. http://dx.doi.org/10.21138/GF.676

de aprendizaje: identifica y evalúa objetivamente los problemas que se plantean en el contexto social en el que vive; plantea soluciones a los problemas surgidos en el contexto en el que vive; se siente responsable de su comportamiento.

\subsubsection{Estrategias didácticas.}

Para plasmar esa forma de entender la formación en actuaciones concretas, la literatura didáctica plantea diferentes fórmulas y estrategias. Nosotros hemos optado por recurrir a la utilización de las que tienen que ver con el Aprendizaje Basado en Proyectos (ABP). Así, Vergara Ramírez (2015) plantea:

Parece, por tanto, evidente que, si de lo que se trata es de formar las competencias y cualidades humanas básicas que se consideran valiosas para el ciudadano del siglo XXI, la tarea del docente no consistirá solo ni principalmente en enseñar contenidos disciplinares descontextualizados, sino en definir y plantear situaciones en las cuales los alumnos puedan construir, modificar y reformular conocimientos, actitudes, habilidades, emociones y valores.

El aprendizaje por proyectos, problemas o casos es la estrategia didáctica coherente con los nuevos modos de entender el aprendizaje y el desarrollo autónomo de la personalidad de los ciudadanos contemporáneos. (pp. 16-17).

Los ABP pueden plantearse como aprendizajes a partir de la resolución de problemas o, de una forma más intensa, como aprendizajes a partir de proyectos en los que se implica toda una etapa formativa o todas las etapas formativas de un centro educativo o varios. Los materiales educativos que presentamos plantean temas "problematizados", como problemas para resolver $\mathrm{y}$, a la vez, ofrecen las herramientas, en muchas ocasiones transversales a los currículos de las diferentes materias, para hacerlo. Estos materiales se ofrecen online, con una estructura ya creada que, para poder adaptarse tanto a las diferentes circunstancias que puedan darse en las aulas de educación secundaria, como a la intensidad que se quiera dar a esta forma de plantear los aprendizajes, conjugan dos criterios:

1. Utilizar el formato de aprendizajes a partir de la resolución de problemas o casos, en la línea y con los objetivos que plantean Prats y Santacana (2011) enfocados a la enseñanza de la Historia:

Que el alumno trabaje de forma activa en clase, proponiendo la resolución de problemas o empleando el discernimiento, la clasificación y la utilización de técnicas, hace que se incorpore este nivel de alfabetización (literacy) que prepara al alumnado para saber leer el lenguaje conjunto de las ciencias sociales. Además, si el planteamiento didáctico supone una simulación del trabajo del historiador... la enseñanza de la Historia servirá también para introducir al alumnado en el método científico (p. 24), y López (2001): las estrategias de enseñanza-aprendizaje orientadas a la resolución de problemas propician un aprendizaje significativo en cuanto explican y ponen a prueba las concepciones del alumno implicadas en la situación problema (p. 57).

Así, nuestros materiales son un conjunto organizado de tareas o problemas a través de los cuales el alumno va a ir descubriendo qué, cómo, dónde, por qué, etc. se dan los procesos trabajados y, a partir del acercamiento a la realidad que permiten las formas 
Velilla Gil, J., Guallart Moreno, C., Laguna Marín-Yaseli, M. (2021). Materiales educativos para trabajar conceptos sobre desarrollo sostenible en las aulas de educación secundaria. GeoFocus (Artículos), Revista Internacional de Ciencia y Tecnología de la Información Geográfica, 27, 55-93. http://dx.doi.org/10.21138/GF.676

de comunicación multiformato, utilizar esas competencias adquiridas para comprender la realidad que le rodea.

2. Ofrecer un amplio abanico de opciones para que los profesores que quieran utilizarlos puedan seleccionar y ordenar temas, conceptos y tareas, según los objetivos didácticos que tengan para enseñar en el contexto concreto en el que lo hacen. Esta opcionalidad permite al profesor:

a. Trabajar con uno o varios mapas, siguiendo o no las indicaciones que aparecen en los materiales.

b. Utilizar una o varias aplicaciones, siguiendo o no las indicaciones que se le ofrecen en el "widget" Indicaciones incluido en la barra de herramientas. Cada aplicación se ofrece con su enlace para facilitar su acceso directo.

c. Trabajar uno o varios de los conjuntos de actividades que se ofrecen, en la forma de Story Maps (Patton, 2014), en cada bloque de contenidos.

d. Trabajar todo un bloque de contenidos.

\subsection{Los SIG como herramientas educativas.}

Los SIG son herramientas fundamentales en la creación del conocimiento geográfico en cuanto se han convertido en instrumentos principales para el análisis del territorio y para su representación. Además, son también potentes herramientas educativas si se utilizan al servicio de objetivos y estrategias didácticas orientadas a conocer y analizar el espacio y las interrelaciones que establecen con él las sociedades humanas (Moreno, 2013). Como señala Roig (2010): la incorporación de las TIC a la educación debe ir unido necesariamente a un proceso de innovación educativa ya que, de lo contrario, estaremos ante escenarios llenos de tecnología, pero vacíos de pedagogía" (p.329). Buzo. (2016, p. 479) especifica:

\section{La integración de las Tecnologías de la Información Geográfica debe hacerse a través de un cambio metodológico que haga que el centro de gravedad de la enseñanza pase del profesorado al alumnado. Que el proceso de enseñanza no sea una mera exposición y repetición de contenidos, sino que los estudiantes se conviertan en constructores de su propio aprendizaje integrando las TIG en este proceso como herramienta fundamental del aprendizaje geográfico activo.}

El potencial educativo de estas herramientas radica en su forma de disponer la información "en capas" sobrepuestas, en la calidad con la que son capaces de representar el territorio y en sus herramientas de análisis (De Miguel et al., 2016). Por ello, facilitan la adquisición de tres destrezas básicas que requiere el saber geográfico:

1. Saber identificar los elementos que conforman los territorios.

2. Saber identificar y comprender las interrelaciones que se dan entre esos elementos y, con ellas, identificar y analizar la multicausalidad que los puede relacionar.

3. Saber diferenciar entre elementos antrópicos y elementos naturales, para analizar y evaluar las consecuencias que tienen las interacciones entre ambos.

Los SIG adoptan dos formatos: el software de escritorio y el software como servicio online (en la nube). Ramos (2010) lo plantea como el debate sobre la educación "en" SIG y "con" SIG (p. 8). El uso de los SIG de escritorio ("en" SIG), generalmente como software de ordenador o desktop, con el fin de que los alumnos aprendan a utilizarlo creemos que tiene poco 


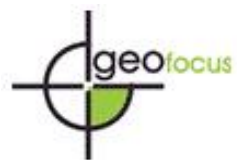

Velilla Gil, J., Guallart Moreno, C., Laguna Marín-Yaseli, M. (2021). Materiales educativos para trabajar conceptos sobre desarrollo sostenible en las aulas de educación secundaria. GeoFocus (Artículos), Revista Internacional de Ciencia y Tecnología de la Información Geográfica, 27, 55-93. http://dx.doi.org/10.21138/GF.676

recorrido, bien porque a esas edades y niveles formativos carecen de los conocimientos y habilidades previas (conceptos geográficos, habilidades de programación, etc.) que se necesitan para esos aprendizajes, bien porque la herramienta en sí misma tiene una complejidad que no hace aconsejable convertir el aprendizaje de su manejo en un tema curricular, ya que estas dificultades suelen ocasionar que, en lugar de utilizar el SIG para aprender geografía, esos aprendizajes sustituyan a los geográficos (Buzo, 2017).

De las experiencias que hemos ido desarrollando en las aulas utilizando SIG con los alumnos, podemos afirmar que estos aprenden pronto el uso del software como servicio online y lo manejan con bastante destreza (Kolvoord, 2012). Presentamos tres ejemplos: dos, resultado del trabajo con SIG con alumnos de tercero de ESO, y otro con alumnos de bachillerato. En estos trabajos siempre ha participado su profesor de Geografía como guía y asesor y, en algunas ocasiones (pocas), para resolver problemas técnicos fuera del alcance de alumnos de esas edades:

- Alumnos de tercero de ESO: Impacts of global warming on a ski resort. The case of Formigal and Panticosa (Aragonese Pyrenees, Spain), en: https://arcg.is/1Dj8HT, y Valoración de equipamientos urbanos, en: https://bit.ly/eq_urban

- Alumnos de segundo de bachillerato: Especialización productiva y comportamientos demográficos. En: https://bit.ly/prod_demograf

Por otro lado, el uso de los SIG no se limita al de su software, supone ser capaz de hacer muchas más cosas que tienen que ver con el desarrollo de las competencias básicas necesarias para un ciudadano de la sociedad del conocimiento (Sinton y Lund, 2007). En primer lugar, supone abordar cualquier tarea formativa con un método que plantea las tareas de aprendizaje como un itinerario para la resolución de un problema para el que se formula una hipótesis científica, que hay que demostrar (Barbas et al., 2014). En el trayecto para conseguirlo, se utilizan destrezas relacionadas con la búsqueda y selección de información objetiva, relevante y pertinente para el objeto de esa búsqueda, también con el tratamiento de la misma para poder obtener índices, tasas, coeficientes, etc., y para adaptarla a los formatos que utilizan los softwares de los SIG. Pero, además de método, también se requiere rigor en el uso y tratamiento de la información. En resumen, el trabajo con SIG no solo implementa la adquisición de competencias geográficas, también lo hace con las que tienen que ver con contenidos lingüísticos, culturales, históricos, naturales, científicos, tecnológicos y sociales (De Miguel et al., 2016), en la línea de las destrezas que en el apartado anterior hemos denominado "de carácter general". Se pueden considerar, por tanto, herramientas transversales utilizables por todas las materias que utilizan análisis territoriales y su representación (Baker et al., 2015).

Esta estrategia didáctica permite que los alumnos-ciudadanos se puedan sentir capaces para comprender el contexto espacial y social en el que viven, para identificar los problemas que en él se dan, y para poder ofrecer soluciones a los mismos (Guallart et al., 2020). Esta percepción de sus capacidades potencia el desarrollo de su autoestima y les permite evaluar adecuadamente su posición en el sistema de relaciones sociales en el que viven y en las que esa sociedad mantiene con su territorio, lo que favorece la expansión de modelos de "aprendizaje-servicio" y de actitudes de compromiso social, medioambiental, etc.

Además, los SIG ya no son sólo herramientas cartográficas y de análisis territorial. En la actualidad están desarrollando tecnologías orientadas a hacer más eficiente el trabajo de sus usuarios, que pueden ser de utilidad en educación (Kerski, 2003 y De Miguel, 2015). Detallamos algunas: 
Velilla Gil, J., Guallart Moreno, C., Laguna Marín-Yaseli, M. (2021). Materiales educativos para trabajar conceptos sobre desarrollo sostenible en las aulas de educación secundaria. GeoFocus (Artículos), Revista Internacional de Ciencia y Tecnología de la Información Geográfica, 27, 55-93. http://dx.doi.org/10.21138/GF.676

1. La cartografía se puede ofrecer como Map Web (un mapa con capas) en el que el usuario-alumno puede trabajar directamente online y luego guardar los resultados, o invertir el proceso y guardar una copia del mapa para luego trabajar con ella. Ese trabajo puede consistir en comparar las informaciones (distribución en el territorio de una información) que el mapa aporta, añadir otras (desde internet, a partir de webs que ofrecen descargas en formatos propios de los SIG o en servicios basados en estándares, como Open Geospatial Consortiun [OGC], o desde su ordenador, en formatos muy extendidos y de fácil manejo, como csv, por ejemplo) o quitarlas; también en realizar análisis sencillos, preconfigurados en el software GIS que se utiliza o diseñados por el profesor, en editar la simbología con la que se representa la información, etc.

Ahora bien, trabajar con alumnos directamente en Map Web plantea algunos problemas: su manipulación puede deteriorarlos o generar copias dañadas que dificultan la utilización de los mismos. Por ello, actualmente los mapas se ofrecen a través de visores o de aplicaciones. Los primeros presentan los mapas elaborados y el usuario-alumno, además de ver la leyenda, puede seleccionar las capas que quiere ver, cambiar el "mapa base", puede comparar la distribución espacial de las informaciones de las dos capas (bien con una herramienta configurada para hacerlo, bien haciendo que la capa superior sea más transparente para poder ver la capa inferior y comparar las dos), y puede utilizar una herramienta de información que genera una ventana emergente en la que se pueden explicar los conceptos necesarios para realizar las tareas que se plantean o estas mismas. Además, los visores permiten imprimir en varios formatos ( $p d f$, jpg, png, gif, etc.) los resultados que está obteniendo el usuarioalumno de su trabajo con el mapa.

Las aplicaciones son algo más completo, ya que, además de indicaciones sobre lo que se representa en el mapa, se pueden incluir herramientas que permiten, entre otras cosas, dibujar o escribir sobre el mapa, añadir información desde el ordenador (archivos csv o shapefile) o desde internet dando lugar a nuevas capas, medir distancias, superficies, etc. o localizar, hacer automáticamente análisis estadísticos de las informaciones representadas, buscar y localizar, utilizar zooms prediseñados sobre el mapa con el objeto de disminuir la escala para poder apreciar más informaciones o hacerlo con más detalle, obtener imágenes del trabajo realizado con los mapas, etc.

En resumen, visores y aplicaciones permiten $\mathrm{ABP}$ a partir del planteamiento de un problema y de las tareas necesarias para solucionarlo utilizando las herramientas necesarias para llevarlas a cabo. Un ejemplo de aplicación puede ser esta, orientada a trabajar con alumnos de $3^{\circ}$ de ESO: https://arcg.is/1SSbCn. Varias aplicaciones pueden dar lugar a un proyecto más complejo y a utilizar estrategias didácticas más complejas, como gamificación, Flipped Classroom. Personal Learning Environment, etc. Un ejemplo puede ser este: https://arcg.is/1Cv8DX.

2. Los SIG como servicio online permiten la creación de "grupos", en este caso, de alumnos que pueden intercambiar información, mapas, etc. bajo la guía y supervisión del profesor que puede, de esta manera, ayudar a los alumnos en las tareas que están realizando o evaluar cómo las están haciendo. De esta forma se potencian la adquisición de competencia en el trabajo cooperativo de los alumnos, y el papel del profesor como guía en sus itinerarios de aprendizaje.

3. Permiten la obtención geolocalizada de información geográfica (o de otro tipo) a partir de sencillas aplicaciones para smartphone que utilizan las nuevas tecnologías de la 
Velilla Gil, J., Guallart Moreno, C., Laguna Marín-Yaseli, M. (2021). Materiales educativos para trabajar conceptos sobre desarrollo sostenible en las aulas de educación secundaria. GeoFocus (Artículos), Revista Internacional de Ciencia y Tecnología de la Información Geográfica, 27, 55-93. http://dx.doi.org/10.21138/GF.676

comunicación para transmitirlas por internet, y que un SIG las pueda disponer sobre un mapa. De esta manera los alumnos, como grupo coordinado por el profesor (diseñador de la aplicación), captan de espacios reales información o la actualizan, y la convierten en una representación cartográfica viva, que se amplía y se actualiza constantemente, generando un saber geográfico colectivo.

4. Utilizan formas de comunicación y transmisión de la información por soportes que van más allá de las infraestructuras físicas tradicionales y de las actuaciones presenciales. En primer lugar, la información se articula en lo que los anglosajones denominan un Story Map: una narración que va suministrando o comunicando información de forma que el receptor recibe las informaciones necesarias y lo hace en un orden que le permite seguir el desarrollo de la trama en la que está inmerso, y comprender el resultado o final de esa story (Patton, 2014). Plantear de esta manera la comunicación requiere de un cierto volumen de informaciones y que estas se ordenen de tal forma que el lector vaya desentrañando la trama (un ejemplo: http://bit.ly/paisajes2019). En educación, la utilización de estas stories puede adquirir el tamaño de un ABP o, con didácticas más convencionales, de una unidad didáctica, en las que las informaciones se ordenan siguiendo dos criterios: la lógica del discurso (identificación de elementos, contextualización, relaciones de causalidad...) y la lógica de la narración o lo que hace que el lector o el alumno se sienta reconfortado por su avance a través de la story. Desde el punto de vista de la lógica del discurso, esta forma de realizar la comunicación permite que las informaciones fluyan hacia el receptor de una forma ordenada, como lo puede hacer un libro o un esquema y mucho mejor que lo conseguido por muchas páginas web, blogs, repositorio de materiales, etc. muchos de los cuales no obedecen a la lógica de lo comunicado, sino a cuándo se ha comunicado, a la actualidad de la información comunicada, etc. En este sentido, no se puede olvidar que la representación visual o espacial de esa lógica es una herramienta fundamental del aprendizaje porque refuerza la comprensión de la misma. Por otro lado, la lógica narrativa es un elemento didáctico muy importante: permite que el narrador cree un ritmo o una secuenciación de la información que el receptor pueda seguir y que lo haga avanzando en la story (el narrador, el diseñador de esos materiales educativos, al editarlos o crearlos ya ha tenido que medir el ritmo de la transmisión de las informaciones, ahora se trata de que el receptor avance por los materiales con el ritmo que necesita para comprenderlos o para resolver las tareas que se le van formulando, lo que se consigue cuando utiliza la rueda del ratón de su ordenador para avanzar por la narración). Pero, además, los formatos que se han utilizado en los materiales educativos que estamos presentando y analizando permiten que el narrador se sitúe en la escena y que pueda ayudar al receptor a entenderla. Esto es, cuando el alumno está trabajando con los materiales en el aula o fuera de ella no está solo: el profesor que los ha diseñado ha previsto dificultades de comprensión, explicaciones de temas y contenidos transversales que apoyan, orientaciones que ayudan o dan pistas al alumno, preguntas cuyas respuestas encaminan por el itinerario adecuado, etc. y todo eso aparece en el momento en el que el profesor cree que va a ser necesario. En nuestros Story Maps (inicialmente maps tenía el significado de mapas o esquemas de contenidos, su uso en SIG tiene un significado geográfico) la pantalla del ordenador en el que se está trabajando o la del videoproyector del aula se divide en dos zonas:

1. Una, la principal, en la que discurre la story, donde se trabajan los conceptos, se alojan las informaciones en forma de mapas, aplicaciones, imágenes, archivos de 


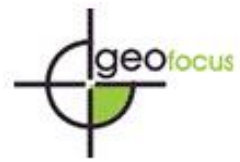

Velilla Gil, J., Guallart Moreno, C., Laguna Marín-Yaseli, M. (2021). Materiales educativos para trabajar conceptos sobre desarrollo sostenible en las aulas de educación secundaria. GeoFocus (Artículos), Revista Internacional de Ciencia y Tecnología de la Información Geográfica, 27, 55-93. http://dx.doi.org/10.21138/GF.676

audio, vídeos, diagramas, esquemas, se realizan las tareas, etc. que aparecen con un orden diseñado por los creadores de los materiales, pero a un ritmo que decide el alumno que los está trabajando.

2. Otra secundaria, más pequeña y situada a un lado de la principal que, como hemos señalado antes, acompaña a la primera con el objetivo de ayudar y guiar al alumno por el itinerario que describe ese Story Map. Esta herramienta es la que permite que los materiales adopten la forma de una comunicación cooperativa (Tomasello, 2008) muy eficiente.

5. Por último, estos Story Maps pueden ser confeccionados con herramientas SIG por usuarios con una escasa formación en su software, simplemente a partir de aplicaciones en las que se dan unas instrucciones y unas herramientas preconfiguradas (widget) para hacerlo. Los resultados son muy buenos educativamente, ya que los alumnos alcanzan un alto nivel de motivación al poder elaborar una story que comunicar (Vergara, 2015), pero, además, al hacerlo, tienen que reflexionar sobre los contenidos que quieren transmitir y sobre cómo hacerlo. Un ejemplo elaborado por alumnos de $4^{\circ}$ de ESO: https://bit.ly/37jVKFq

6. Story Maps, aplicaciones, mapas, etc. pueden integrarse en Hubs, que son plataformas online en las que los miembros de uno o varios grupos de trabajo pueden trabajar de forma cooperativa agregando contenidos, cooperando con otros miembros en su elaboración o en su mejora, en su difusión, etc. (ESRI, 2020). Cada bloque de contenidos, excepto el dedicado al cambio climático, se ofrece en un $H u b$.

\subsection{Los temas en el currículo español de Educación Secundaria.}

En este punto, parece adecuado indicar la relevancia y la urgencia de incluir de forma transversal el concepto de "sostenibilidad" (Naciones Unidas (s.f.), "los Objetivos de Desarrollo Sostenible") en los currículos educativos, ya que, como afirma Granados (2011), el desarrollo sostenible es:

la capacidad de las sociedades para resolver problemas; es siempre una cuestión de compromiso activo para encontrar soluciones, aprovechar oportunidades y crear perspectivas, asumiendo que no existe una respuesta a largo plazo. Es como un juego en el que podemos perder, pero que nunca podremos ganar de manera definitiva, porque la sostenibilidad es mantenerse jugando, es tener la habilidad de solucionar los problemas entre todos, en un contexto complejo, incierto y cambiante (p. 29).

Las competencias asociadas a la sostenibilidad son, pues, herramientas esenciales para la formación de una nueva ciudadanía que pueda hacer frente a los retos que hoy tienen planteados las sociedades y estas con el medio en el que habitan. Por ello, ya se está desarrollando la llamada Educación para el Desarrollo Sostenible, que no es sino la formación en esas competencias que lo hacen posible (Boulahrouz, 2018).

En los materiales que presentamos, los tres bloques de contenidos se plantean a partir de cuatro conceptos "clave" (Paniagua, Bryant y Kizos, 2012): la despoblación, la problemática del mundo rural, el patrimonio natural y cultural, y el cambio climático. Estos se hilvanan a partir del concepto de sostenibilidad. La transversalidad de este concepto (Moreno-Latorre et al., 2017) viene tanto de su armazón conceptual, como de que para abordarlo educativamente sea necesario utilizar o aprender destrezas como localizar, comprender y analizar el relieve, los 


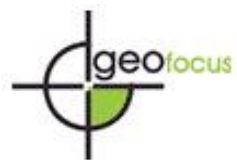

Velilla Gil, J., Guallart Moreno, C., Laguna Marín-Yaseli, M. (2021). Materiales educativos para trabajar conceptos sobre desarrollo sostenible en las aulas de educación secundaria. GeoFocus (Artículos), Revista Internacional de Ciencia y Tecnología de la Información Geográfica, 27, 55-93. http://dx.doi.org/10.21138/GF.676

climas, la vegetación, la hidrología, la edafología, la demografía, las actividades económicas, los desequilibrios territoriales y las políticas de ordenación del territorio, etc., que son los campos del saber geográfico (transversalidad en geografía). Pero, además, son necesarias otras competencias que atañen a la geografía y también a otras ciencias (Collazo et al. 29-31 de marzo, 2017), como medir, buscar y obtener información que sea objetiva, pertinente y relevante para lo estudiado, ser capaces de tratarla con las herramientas adecuadas y utilizarla para identificar problemas, analizarlos para comprender sus orígenes, y evaluar las posibilidades de resolverlos. En este caso, se trata de transversalidad curricular (Velásquez, 2009 y Tarradellas et al, 2017)

Esta transversalidad es la que permite tres estrategias didácticas de gran valor formativo:

1. El aprendizaje-servicio, sobre el que Puig Rovira et al. (2011) indican: no hace falta insistir en el valor que el aprendizaje-servicio tiene para los niños y los jóvenes en formación respecto al aprendizaje de competencias, habilidades y valores (p. 61). Además, el propio concepto de sostenibilidad lleva implícita la actuación para asegurarla. Como señalan Tarradellas et al. (2017, p. 4): el concepto de Educación para la Sostenibilidad se puede resumir como la voluntad de cambiar la manera de vivir para hacer un mundo mejor en los ámbitos ambiental, social y económico. Más explícito, Valera et al, (2014), citando a Ferreira (2009) y a Kyburz-Graber (2013), utilizando Educación Ambiental (EA) como sinónimo de Educación para la Sostenibilidad, señala:

\begin{abstract}
Es necesario destacar que la EA (Educación Ambiental) es un proceso intencional, sostenido en el tiempo, que implica la adquisición de conocimientos conceptuales y valores, así como el desarrollo de actitudes, aptitudes y modos de actuar en interacción social. Tal proceso no puede ser desarrollado en exclusiva, ni de manera aislada, por los sistemas educativos e implica procesos de educación formal y no formal.
\end{abstract}

Esta problemática ha provocado que se haya señalado la necesidad de orientar la EA hacia el desarrollo de una competencia para la acción (p. 28)

2. Es por ello que, en los tres bloques de contenidos, además de tareas más convencionales, se ofrecen otras relacionadas con el desarrollo rural o la lucha contra el cambio climático, que requieren entrar en contacto con instituciones $u$ organizaciones de ese ámbito para recibir orientaciones y apoyo, y para intentar colaborar en las actuaciones que llevan a cabo.

3. El Aprendizaje Basado en Proyectos (ABP). Sobre el potencial de la sostenibilidad para implementar este tipo de aprendizajes es interesante ver y escuchar la sesión formativa que impartió Bob Lenz, en la Escuela de Virolai, en Barcelona (UNESCOCAT, 11 de julio de 2019). También resultan muy significativas las palabras de Valera et al. (2014, p. 29) citando a Álvarez y Vega, (2009): una EA orientada hacia la acción requiere de enfoques globalizadores, orientados a la resolución de problemáticas socioambientales que implique una reflexión y búsqueda de soluciones que consideren a todas las partes implicadas. Por ello, como indicábamos antes, los materiales que presentamos utilizan la estrategia didáctica de los aprendizajes basados en la solución de problemas que forman parte de una forma relevante del contexto en el que desarrolla su vida el alumno.

Habiendo ponderado la importancia de la inclusión de los conceptos "clave" antes enunciados, vamos a analizar su tratamiento en la normativa educativa española actual. 


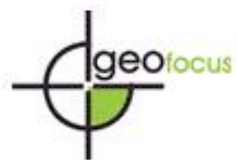

Velilla Gil, J., Guallart Moreno, C., Laguna Marín-Yaseli, M. (2021). Materiales educativos para trabajar conceptos sobre desarrollo sostenible en las aulas de educación secundaria. GeoFocus (Artículos), Revista Internacional de Ciencia y Tecnología de la Información Geográfica, 27, 55-93. http://dx.doi.org/10.21138/GF.676

Utilizaremos la LO 8/2013, desarrollada en la Orden ECD/1361/2015, en cuyos anexos aparecen, para cada materia o asignatura, los bloques de contenidos (BC), los criterios de evaluación (CE) y los estándares de aprendizaje evaluables (EA) que tienen carácter normativo, aunque las administraciones autonómicas con competencias en materia educativa puedan adaptarlos.

\subsubsection{Los procesos de despoblación}

No aparecen de forma explícita en los currículos de ESO y Bachillerato. Cabría suponerlos incluidos en los $\mathrm{BC}$ relacionados con el reparto de la población, las migraciones, los procesos de urbanización y de industrialización. En segundo de ESO, en el BC 1, titulado "El espacio humano: España y Europa. España: la población, características generales, etc.”, el CE 1 aclara lo que se pretende que aprendan los alumnos: "analizar las características de la población española, su distribución, dinámica y evolución, así como los movimientos migratorios", pero es en los EA 1.1 y EA 1.2 cuando se concreta lo que se espera que sepan hacer: "explicar una pirámide de población de España y de las diferentes comunidades autónomas", y "analizar en los distintos medios los movimientos migratorios en las tres últimas décadas". De esta forma, los procesos de despoblación quedan fuera del currículo, que opta por centrarse en la estructura demográfica "española" y "de las diferentes comunidades autónomas", espacios que no sirven para evaluar el diferente reparto en el territorio, y los movimientos migratorios desde 1995, cuando comienza la llegada masiva de inmigrantes extranjeros a España. En tercero de ESO sucede algo similar: en el BC 1, "Geografía. El espacio humano: el Mundo. La población mundial. Reparto desigual y factores que lo explican. Movimientos naturales. Las migraciones: evolución y tendencias", que, aunque se plantea una escala mundial, enuncia contenidos y procesos que podrían explicar la despoblación. Cuando vamos al CE 1, se formulan requerimientos de aprendizaje que pueden dar lugar a los relacionados con la despoblación: "comentar la información en mapas del mundo sobre la densidad de población y las migraciones", pero los EA 1.1 y EA 1.3, que concretan este criterio, dicen: "localiza en el mapa mundial los continentes y las áreas más densamente pobladas" y "explica el impacto de las oleadas migratorias en los países de origen y en los de acogida". En resumen, el tratamiento de la distribución de la población se plantea a una escala en la que no se puede tratar la despoblación en España y los movimientos migratorios interiores relacionados con ella quedan en el olvido.

En bachillerato, comienzan a aparecer esos contenidos. Curiosamente es en Historia del Mundo Contemporáneo (primero de bachillerato), cuando, en el BC 2: "Las revoluciones industriales y sus consecuencias sociales: Cambios debidos a la Revolución Industrial: transportes, agricultura, población (migraciones y el nuevo concepto de ciudad)" se plantea la conexión entre industrialización y migraciones, que se concretan en el CE 3: "identificar los cambios en los transportes, agricultura y población que influyeron o fueron consecuencia de la Revolución Industrial del siglo XIX", pero en los EA no aparece ninguno que se refiera al llamado "éxodo rural", los tres estándares que hay se centran en "cambios sociales", "cambios en el plano de la ciudad" y "formas de vida en las ciudades".

En la asignatura de Geografía de segundo de bachillerato ya aparecen contenidos relacionados con la despoblación, aunque sin mencionarlos de una forma explícita. En el BC 6, "La población española. Distribución territorial de la población. Las Migraciones", los CE 4 y CE 9, focalizan esos contenidos en las relaciones entre las migraciones y el reparto de la población, y en la existencia de desigualdades territoriales, que se concretan en los EA 4.1, "explica los procesos migratorios antiguos que afectan a España", EA 4.2, "identifica y analiza 


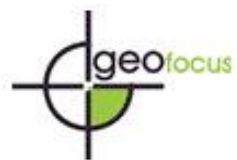

Velilla Gil, J., Guallart Moreno, C., Laguna Marín-Yaseli, M. (2021). Materiales educativos para trabajar conceptos sobre desarrollo sostenible en las aulas de educación secundaria. GeoFocus (Artículos), Revista Internacional de Ciencia y Tecnología de la Información Geográfica, 27, 55-93. http://dx.doi.org/10.21138/GF.676

las migraciones recientes", y EA 5.1, "comenta el mapa de la densidad de población actual en España". Este planteamiento se enriquece con el BC 10, "El espacio urbano. Características del proceso de urbanización", que en los CE 4 y CE 9 ya trata el proceso de urbanización y sus repercusiones en la ordenación del territorio, aunque no acaba de quedar claro si el proceso de urbanización se entiende sólo y exclusivamente como el de crecimiento de las ciudades, ya que ningún EA hace alusión al éxodo rural. El BC 11, "formas de organización territorial. Los desequilibrios y contrastes territoriales", que podría incluir contenidos sobre los desequilibrios entre lo rural y lo urbano o sobre los espacios despoblados y los de fuerte concentración de la población, se orientan a valorar los desequilibrios entre comunidades autónomas, como queda claro en el CE 4: "analizar la organización territorial española describiendo los desequilibrios y contrastes territoriales y los mecanismos correctores", que se concreta en el EA 4.3: "enumera los desequilibrios y contrastes territoriales existentes en la organización territorial española".

De esta forma, parece evidente que los procesos de despoblación que han configurado el reparto desequilibrado de la población y los recursos en España (Collantes y Pinilla, 2011 y García et al., 1996), y que se encuentran detrás del fuerte envejecimiento de los espacios rurales, son tratados poco, tarde y de forma secundaria, asociados a la industrialización y modernización de la economía española, como algo necesario para el desarrollo económico y social (Velilla y Laguna, 2019), y sin analizar nunca cómo se llevó a cabo y cómo sus consecuencias son un problema que hay que resolver.

\subsubsection{El mundo rural y su problemática}

No aparece en el currículo de ESO como tal y solo cabe pensar que se incluye en los contenidos sobre actividades agrarias y sobre paisajes humanizados. Así, en segundo de ESO, en el BC 1 de contenidos leemos: "el espacio humano: España y Europa: España... la acción humana sobre el territorio... los paisajes humanizados; las ciudades", que se aclaran en los CE 5, “identificar los principales paisajes humanizados españoles, identificándolos por comunidades autónomas", y CE 9: "comprender el proceso de urbanización, sus pros y contras en Europa". Los EA concretan. El EA 3.1. dice: "compara paisajes humanizados españoles según su actividad económica", y el EA 9.2: "resume elementos que diferencien lo urbano y lo rural en Europa". En estos planteamientos se observa cómo se utilizan como sinónimos espacios y paisajes y como se sugiere que las actividades económicas desarrolladas en un espacio son el elemento que diferencia si es rural (espacio o paisaje agrario) o si es urbano (actividades de los sectores secundario y terciario). En el currículo de tercero de ESO, a pesar de que en el BC 1 se explicita contenido sobre "tipos de paisajes agrarios. Explotación forestal y marina.", en los CE y los EA no se plantea ningún contenido que tenga que ver con esos espacios ni con paisaje alguno.

En Geografía de segundo de bachillerato, además de los contenidos, criterios y estándares sobre población ya citados en párrafos anteriores, en el BC 7 aparece por primera vez el concepto de espacio rural, pero inmediatamente se relaciona con las actividades agrarias. Dice así: "el espacio rural y las actividades del sector primario: El peso de las actividades agropecuarias, forestales y pesqueras en el PIB. La población activa", y a continuación, pasa a enumerar los elementos y factores que configuran los paisajes agrarios. Esta identificación rural-agrario se observa claramente en los CE 2 ("distinguir los paisajes agrarios estableciendo sus características"), CE 3 ("analizar adecuadamente un paisaje rural distinguiendo el terrazgo, bosques y hábitat" (sic) (obsérvese que utiliza conceptos del análisis de paisajes agrarios), y CE 9 (“obtener y seleccionar información de contenido geográfico relativo al espacio rural, silvícola o pesquero utilizando fuentes disponibles tanto en Internet, medios de comunicación social o 


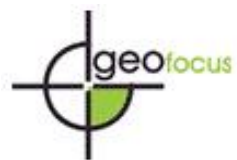

Velilla Gil, J., Guallart Moreno, C., Laguna Marín-Yaseli, M. (2021). Materiales educativos para trabajar conceptos sobre desarrollo sostenible en las aulas de educación secundaria. GeoFocus (Artículos), Revista Internacional de Ciencia y Tecnología de la Información Geográfica, 27, 55-93. http://dx.doi.org/10.21138/GF.676

bibliografía"). Los contenidos del BC 11, versan sobre "desequilibrios y contrastes territoriales", pero se centran en el análisis de los ocasionados por la organización territorial, entendida como la organización político-administrativa. En resumen, los espacios rurales y su problemática quedan reducidos a la identificación y análisis de los espacios agrarios y de los problemas de agricultura y ganadería, siendo imposible plantear los problemas demográficos, de renta, de accesibilidad a los servicios, etc. del mundo rural, o los desequilibrios en el reparto de esas problemáticas en el territorio español, entre espacios rurales y espacios urbanos.

Estas ausencias contrastan con las propuestas de la Comisión Europea para la "nueva política de conexión" a partir de 2020, donde entre las cinco prioridades de inversión para el período 2021-2027, se puede leer: una Europa más social, que haga realidad el pilar europeo de derechos sociales y que apoye el empleo de calidad, la educación, las capacidades educativas y profesionales, la inclusión social y la igualdad de acceso a la asistencia sanitaria (European Commission, 2020)

\subsubsection{Sobre los patrimonios natural y cultural}

Hasta segundo de Bachillerato no aparece mención alguna. En los contenidos de historia, en primero de ESO, se pueden leer CE como estos: "entender la trascendencia de los conceptos "Democracia" y "Colonización" (CE 16), "entender el alcance de "lo clásico "en el arte occidental" CE 19) o "establecer conexiones entre el pasado de la Hispania romana y el presente" (CE 22). Es decir, se trata de dar relevancia a conceptos y procesos que han influido en nuestras actuales formas culturales, sociales, etc. Lo más parecido a lo que entendemos por patrimonio artístico lo encontramos en el EA 22.2: "analiza diversos ejemplos del legado romano que sobreviven en la actualidad". En los siguientes cursos de ESO prácticamente desaparecen este tipo de BC, CE ni EA. En los contenidos de geografía, en ESO, lo que más se aproxima al concepto de patrimonio natural es la caracterización (peculiaridades) del medio físico español y la identificación de los espacios naturales españoles y, en segundo de ESO, de los espacios naturales protegidos. Así, en el primer curso, en el BC 1 se plantea: "geografía: el medio físico: medio físico de España, Europa y el mundo..." y en los CE 3: "describir las peculiaridades del medio físico español" y CE 9: "conocer los principales espacios naturales de nuestro continente". En segundo, en el BC 1: "el espacio humano: España y Europa: España...”, se establecen los CE 4: "conocer los principales espacios naturales protegidos a nivel peninsular e insular" (se desarrolla en el EA 4.1: "sitúa los parques naturales españoles en un mapa, y explica la situación actual de algunos de ellos), y CE 5: "identificar los principales paisajes humanizados españoles, identificándolos por comunidades autónomas".

En bachillerato, en Historia del Arte, sí que comienza a citarse ya el tema del patrimonio artístico. Hasta la segunda mitad del siglo XX se mantiene un esquema de tratamiento del "patrimonio" similar. Por un lado, plantea la pervivencia de formas culturales y artísticas del pasado en nuestras manifestaciones culturales actuales, y por otro, plantea la conservación de las obras más relevantes, atendiendo a su calidad e importancia. Un ejemplo lo tenemos en el BC 1: "raíces del arte europeo: el legado del arte clásico", con su CE 5: "respetar las creaciones artísticas de la Antigüedad grecorromana, valorando su calidad en relación con su época y su importancia como patrimonio escaso e insustituible que hay que conservar", que se desarrolla en el EA 5.1: "confecciona un catálogo, con breves comentarios, de las obras más relevantes de arte antiguo que se conservan en su comunidad autónoma". Al llegar al BC 6 ("la universalización del arte desde la segunda mitad del siglo XX") ya se aborda directamente el concepto de patrimonio y se asocia a la necesidad de conservarlo. Así, en BC, se establece "el patrimonio artístico como riqueza cultural. La preocupación por su conservación", que el CE 5 


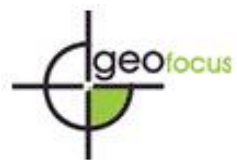

Velilla Gil, J., Guallart Moreno, C., Laguna Marín-Yaseli, M. (2021). Materiales educativos para trabajar conceptos sobre desarrollo sostenible en las aulas de educación secundaria. GeoFocus (Artículos), Revista Internacional de Ciencia y Tecnología de la Información Geográfica, 27, 55-93. http://dx.doi.org/10.21138/GF.676

aclara: "explicar qué es el Patrimonio Mundial de la UNESCO, describiendo su origen y finalidad" y el EA 5.1 concreta: "explica el origen del Patrimonio Mundial de la UNESCO y los objetivos que persigue". Esta referencia a los "objetivos" lleva al planteamiento de la conservación, de los elementos identitarios del patrimonio, etc. que ya nos sitúan en una forma de abordar el patrimonio más completa.

Algo similar sucede en los contenidos geográficos: el BC 5 incluye "los paisajes naturales y las interrelaciones naturaleza-sociedad: los paisajes naturales españoles, sus variedades. Políticas favorecedoras del patrimonio natural", citando ya patrimonio natural, aunque lo focaliza en los paisajes naturales, olvidando los culturales o humanizados que son testimonio de antiguas formas de utilización de esos espacios. Además, al hablar de las "políticas favorecedoras", está añadiendo contenidos conservacionistas. Esto se observa claramente en los CE 1: "describir los paisajes naturales españoles identificando sus rasgos", CE 2: "reflejar en un mapa las grandes áreas de paisajes naturales españoles", CE 3: "describir los espacios humanizados enumerando sus elementos constitutivos", CE 4: "relacionar el medio natural con la actividad humana describiendo casos de modificación del medio por el hombre" y CE 5: "obtener y seleccionar información de contenido geográfico relativo a los paisajes naturales y las interrelaciones naturaleza-sociedad utilizando fuentes en las que se encuentre disponible, tanto en Internet, bibliografía o medios de comunicación social”. Los estándares de aprendizaje refuerzan esa idea de protección frente a actuaciones humanas en el medio natural insostenibles. En el EA 3.1, se concreta "identifica y plantea los problemas suscitados por la interacción hombre-naturaleza sobre los paisajes", en el EA 5.2: "selecciona y analiza a partir de distintas fuentes de información noticias periodísticas o imágenes en las que se percibe la influencia del hombre sobre el medio" y en el EA 5.3: "obtiene y analiza la información que aparece en los medios de comunicación social referida a la destrucción del medio natural por parte del hombre".

En resumen, el tratamiento del patrimonio, tanto cultural como natural, es mucho más rico que el que han obtenido los procesos de despoblación o el mundo rural, aunque se concentra en bachillerato.

\subsubsection{El cambio climático.}

En ESO, sólo aparece en cuarto curso. En primero, segundo y tercero se da una evolución en los contenidos ambientales abordados que se inicia con la identificación de los problemas medioambientales y la acción humana en el medio, en primero, para pasar a plantear los conceptos de contaminación y desarrollo sostenible y a iniciar el de conservación con los "parques naturales", en segundo. En tercero se aborda el "desarrollo sostenible", el aprovechamiento y futuro de los recursos naturales y las energías alternativas. En cuarto curso aparece finalmente el "calentamiento global", pero lo hace de una forma peculiar. El BC 10 fija lo siguiente: "la relación entre el pasado, el presente y el futuro a través de la Historia y la Geografía". Esta complejidad pretende ser aclarada por el CE 1, que establece: "reconocer que el pasado "no está muerto y enterrado", sino que determina o influye en el presente y en los diferentes posibles futuros y en los distintos espacios". El EA 1.1, destinado a concretar a qué cuestión debe poder responder un alumno o qué tarea saber realizar para evaluar sus aprendizajes, aclara: "plantea posibles beneficios y desventajas para las sociedades humanas y para el medio natural de algunas consecuencias del calentamiento global, como el deshielo del Báltico", que da fin a la peculiaridad en el tratamiento del cambio climático en el currículo de la ESO. 


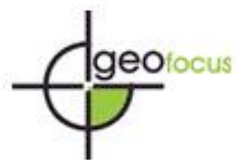

Velilla Gil, J., Guallart Moreno, C., Laguna Marín-Yaseli, M. (2021). Materiales educativos para trabajar conceptos sobre desarrollo sostenible en las aulas de educación secundaria. GeoFocus (Artículos), Revista Internacional de Ciencia y Tecnología de la Información Geográfica, 27, 55-93. http://dx.doi.org/10.21138/GF.676

En bachillerato este tratamiento es más sencillo. Los temas medioambientales se plantean en dos BC. En el BC 1: "la geografía y el estudio del espacio geográfico: el territorio como espacio de relaciones humanas y sociales especializadas. El territorio centro de interacción de las sociedades: el desarrollo sostenible. El concepto de paisaje como resultado cultural", orienta el tema hacia las repercusiones de la actividad humana sobre el espacio que es su hábitat. El CE 2 fija "identificar el espacio geográfico como tal en sus diversas ocupaciones, entendiéndolo como centro de relaciones humanas y sociales", concretando en el EA 2.1: "identifica los distintos paisajes geográficos". El BC 3 se centra en temas relacionados con el calentamiento global: "la diversidad climática y la vegetación. Dominios climáticos españoles: su problemática", aunque luego el CE 7 causa cierto desconcierto al fijar: "obtener y seleccionar información de contenido geográfico relativo a la diversidad climática de España utilizando las fuentes disponibles, tanto de Internet, como de medios de comunicación social, o bibliografía, que se concreta en el EA 7.1: "analiza cómo afecta a España el cambio climático". De la lectura del conjunto parece deducirse que las consecuencias del cambio climático se plantean como los cambios en las características (elementos del clima) de los dominios climáticos (españoles), sin atender a sus causas, ni a sus consecuencias más allá del propio calentamiento o los cambios en la cantidad e intensidad de las precipitaciones.

Ante la amenaza real del cambio climático y los compromisos adquiridos por España con el Acuerdo de París (United Nations, 2020) contra el cambio climático (ratificado por España el 12 de enero de 2017) y con la Agenda 2030 y los Objetivos de Desarrollo Sostenible (Programa de Naciones Unidas para el Desarrollo [PNUD], 2020), el décimo tercero de los cuales se denomina acción por el clima, parece contradictorio que, desde el currículo educativo no se tenga como objetivo prioritario la formación para hacer a los ciudadanos competentes para hacer frente a esa amenaza.

Estas insuficiencias y, en ocasiones, ausencias de los cuatro conceptos "clave", en los currículos educativos de Geografía e Historia han sido uno de los motivos por los que los hemos abordado en los materiales educativos, con la intención de ayudar a paliar esos problemas o llenar esos déficits. Por otro lado, el carácter "problemático" de los mismos ha favorecido las estrategias didácticas orientadas hacia el aprendizaje a partir de la resolución de problemas $(\mathrm{ABP})$ y a potenciar la adquisición de competencias.

\section{Los materiales}

Los materiales que aquí se presentan se encuentran online en los localizadores de recursos online (URL) que indicaremos más adelante en cada bloque temático. Son públicos y se ofrecen a quien los quiera utilizar de forma totalmente gratuita. Su utilización no está sometida a criterio o norma alguna, exceptuando las indicadas en la licencia Creative Commons de Atribución-No Comercial-Sin Derivadas 4.0 Internacional (CC BY-NC-ND 4.0, en: https://creativecommons.org/licenses/by-nc-nd/4.0/deed.es_ES). De tal forma, que se ofrece para que un profesor o un usuario pueda:

A. Trabajar con uno o varios mapas, siguiendo o no las indicaciones que aparecen en los materiales.

B. Utilizar una o varias aplicaciones, siguiendo o no las indicaciones que se le ofrecen en el "widget" indicaciones, que se encuentra en la barra de herramientas. Cada aplicación se ofrece con su enlace para que pueda ser reutilizado, pero siempre siguiendo las indicaciones de la citada licencia. 


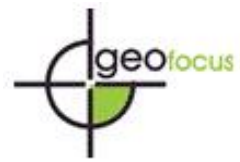

Velilla Gil, J., Guallart Moreno, C., Laguna Marín-Yaseli, M. (2021). Materiales educativos para trabajar conceptos sobre desarrollo sostenible en las aulas de educación secundaria. GeoFocus (Artículos), Revista Internacional de Ciencia y Tecnología de la Información Geográfica, 27, 55-93. http://dx.doi.org/10.21138/GF.676

C. Trabajar, con las mismas opciones y las mismas limitaciones, uno o varios de los conjuntos de actividades que se ofrecen, en la forma de Story Maps, en cada bloque de contenidos.

D. Trabajar todo un bloque de contenidos en las mismas condiciones.

\subsection{Los procesos de despoblamiento en Aragón.}

Los contenidos se encuentran organizados en capítulos en un "Hub" con ese título, que se localiza en esta URL: https://bit.ly/despoblacion_aragon. Cada capítulo es un Story Map en el que se abordan contenidos y tareas de una forma organizada. Sus títulos y los contenidos y problemas planteados son:

\subsubsection{La despoblación en Aragón. Los despoblados.}

Se localiza en: https://arcg.is/1uKPLu0, con los siguientes subcapítulos:

A. ¿Qué es esto? Donde se presentan los materiales y se dan las indicaciones básicas para su uso.

B. Los despoblados abordan los procesos de despoblación desde tres perspectivas: la percepción del abandono y ruina de los edificios, de las parcelas agrícolas, etc., la vivencia de ese abandono por la población que emigró hacia otros territorios, y el relato que esa población hizo de cómo vivían en aquellos territorios y cómo fueron percibiendo las primeras salidas o marchas de población.

C. Aragón. Parte de la localización de los núcleos de población despoblados: núcleos de población que, en 1888, tenían quince o más habitantes y actualmente están despoblados o amenazados gravemente de estarlo. Avanzando se encuentran las tareas que abordan la despoblación desde la perspectiva del descenso en la intensidad de la intervención antrópica en el territorio.

\subsubsection{La despoblación en Aragón. Causas.}

Se localiza en: https://arcg.is/8irLf. Tiene los siguientes subcapítulos:

A. Causas económicas: análisis de los problemas de productividad y rentabilidad de las actividades agrarias con respecto a los otros sectores y actividades económicas, relacionándolo con la emigración.

B. Accesibilidad analiza las diferencias territoriales en el acceso a servicios básicos, ejemplificados en la atención sanitaria, y su relación con la localización de la despoblación.

C. Lo rural aborda cómo percibía lo rural y lo urbano la población que participó en el "éxodo rural" y, también, el resto de los ciudadanos españoles.

3.1.3. Despoblación en Aragón. Factores espaciales.

Se localiza en: https://arcg.is/0WObj50. Tiene los siguientes subcapítulos: 


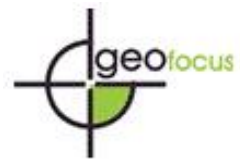

Velilla Gil, J., Guallart Moreno, C., Laguna Marín-Yaseli, M. (2021). Materiales educativos para trabajar conceptos sobre desarrollo sostenible en las aulas de educación secundaria. GeoFocus (Artículos), Revista Internacional de Ciencia y Tecnología de la Información Geográfica, 27, 55-93. http://dx.doi.org/10.21138/GF.676

A. El relieve, donde se analizan las altitudes en las que se concentran los despoblados y se relacionan con dos conceptos: "espacios desfavorecidos" y zonas de "turismo de nieve y montaña”.

B. Embalses y pantanos aborda los impactos que la construcción de esas infraestructuras y el crecimiento de las zonas de regadío tuvieron en la despoblación.

C. La accesibilidad trata las relaciones entre la localización de las zonas con mayor intensidad despobladora y las que tenían mayor dificultad para acceder a las redes más eficientes del transporte por carretera.

D. La proximidad plantea las relaciones de atracción o expulsión que se dieron y se dan entre los núcleos de población en los que se estaban dando procesos de modernización económica y aquellos otros situados próximos a ellos en los que no se daban esos procesos.

\subsubsection{Modelos de despoblación en Aragón.}

En: https://arcg.is/libbly. Plantea siete formas en las que se llevaron a cabo los procesos despobladores, relacionándolas con las causas que los produjeron y las repercusiones que tuvieron en el territorio. Cada modelo tiene dedicado un subcapítulo. De forma general, se puede afirmar que hay dos grandes tipos de procesos despobladores:

1. Aquellos en los que la población salió "voluntariamente" de los territorios en los que había vivido durante muchas generaciones hacia otros en los que creía que iba a vivir mejor.

2. Aquellos en los que la población fue expulsada del territorio en el que vivía, bien por la construcción de infraestructuras, bien por la expansión territorial de otros núcleos de población o de otras actividades económicas.

\subsubsection{Consecuencias demográficas.}

En: https://arcg.is/0GeT8a. Tiene cuatro subcapítulos:

1. Algunas ideas. Donde se abordan las palabras, ideas preconcebidas y prejuicios que circulan en torno a los procesos de despoblación ocurridos o que están ocurriendo en España y, más concretamente, en Aragón.

2. El reparto trata sobre la distribución actual de la población y la que había en etapas anteriores.

3. El envejecimiento de la población. Se representa cartográficamente la distribución municipal de la Tasa de Envejecimiento y se relaciona con las migraciones y la despoblación.

4. El crecimiento de la población se analiza de dos formas: a partir de tablas de número de habitantes según el tamaño del municipio de residencia y a partir de la distribución municipal del Crecimiento Real de la misma. Se identifican los cambios en esa distribución y sus causas. 
Velilla Gil, J., Guallart Moreno, C., Laguna Marín-Yaseli, M. (2021). Materiales educativos para trabajar conceptos sobre desarrollo sostenible en las aulas de educación secundaria. GeoFocus (Artículos), Revista Internacional de Ciencia y Tecnología de la Información Geográfica, 27, 55-93. http://dx.doi.org/10.21138/GF.676

\subsubsection{Despoblación y medioambiente, en Aragón.}

En: https://arcg.is/11buGa. Trata sobre los problemas medioambientales que origina la despoblación y, también, de las posibilidades de mejora medioambiental que puede suponer. Tiene cuatro subcapítulos:

1. La acción humana. En el que se analizan los cambios producidos en el territorio al despoblarse, utilizando fotografías aéreas históricas y actuales.

2. La intensidad es un subcapítulo que, a partir del análisis del mapa forestal de vegetación potencial analiza si se ha producido, en un territorio despoblado, un regreso a la situación del medio natural anterior a las transformaciones producidas por el hombre (Ellis et al., 2010). Se analiza también el mapa de cambios en los usos del suelo entre 1990 y 2012 (European Environment Agency, 21-12-2020) adaptado para uso educativo y, posteriormente, se analizan los impactos de la despoblación en el Potencial Ecológico Neto, la biodiversidad y los riesgos naturales.

3. La vegetación. Para identificar los cambios reales ocurridos en la vegetación entre la etapa del "éxodo rural" y la actualidad, se compara el Mapa Forestal de 1966 y el actual.

4. Oportunidades analiza las posibilidades de reconstrucción del medio natural que abre la despoblación y las dificultades que se presentan.

\subsubsection{La España vaciada.}

En: https://arcg.is/5ieLf. Comienza describiendo como ha sido el despertar de la conciencia ciudadana contra los desequilibrios en el reparto territorial de las rentas, el envejecimiento demográfico, la accesibilidad a los servicios, etc. y continúa presentando ideas y movimientos sociales contra esta situación.

\subsubsection{Algo más.}

En: https://arcg.is/n0GiD0. Ofrece contenidos y tareas complementarios: una recapitulación de lo tratado en los materiales anteriores, tareas sobre la importancia de las capitales municipales en el reparto de la población y el despoblamiento y para profundizar en las diferencias territoriales en el crecimiento de la población y, para acabar, una actividad con la que, de una forma intuitiva y visual, poder sacar conclusiones.

3.1.9. Las fuentes de las que se han obtenido los datos, imágenes, recursos, etc. con los que se han creado los contenidos:

A. Biblioteca Nacional de España. (2020). Biblioteca Digital Hispánica. Ministerio de Cultura y Deporte de España. Recuperado el 28 de noviembre de 2020 de http://www.bne.es/es/Catalogos/BibliotecaDigitalHispanica/Inicio/index.html\#.

Obtenido el Nomenclátor de España, en 1888.

B. Confederación Hidrográfica del Ebro. (25 de septiembre de 2020). Geoportal SITEbro. Ministerio para la Transición Ecológica y el Reto Demográfico. Recuperado el 2 de noviembre de 2020 de http://iber.chebro.es/geoportal/. Obtenidos datos y archivos en formato SIG sobre redes hidrológicas y sobre regadío en la cuenca del Ebro. 
Velilla Gil, J., Guallart Moreno, C., Laguna Marín-Yaseli, M. (2021). Materiales educativos para trabajar conceptos sobre desarrollo sostenible en las aulas de educación secundaria. GeoFocus (Artículos), Revista Internacional de Ciencia y Tecnología de la Información Geográfica, 27, 55-93. http://dx.doi.org/10.21138/GF.676

C. Discomap (21 de diciembre de 2020) Discover Map Services. European Environment Agency. Recuperado el 22 de diciembre de 2020 de https://discomap.eea.europa.eu/Index/. Obtenidos archivos en formato shapefile y Servicios Web (OGC, INSPIRE) sobre: usos del suelo (Corine Land Cover), biodiversidad, Urban Atlas y bosques.

D. Nomenclátor Geográfico de Aragón. (octubre de 2020). Infraestructura de Datos Espaciales de Aragón. Recuperado el 25 de octubre de 2020 de https://idearagon.aragon.es/toponimia/. Datos obtenidos: conjunto de nombres oficiales georreferenciados sobre cartografía topográfica a escala 1:10.000 o mayores.

E. Aragón Open Data. (24 de julio de 2020). Banco de datos. Instituto Aragonés de Estadística del Gobierno de Aragón. Recuperado el 1 de diciembre de 2020 de https://opendata.aragon.es/datos/catalogo. Obtenidos datos de población municipal, actividades económicas, superficies espaciales, etc.

F. Atlas Nacional de España. (2020). Instituto Geográfico Nacional. http://www.ign.es/web/ign/portal/ane-area-ane. Datos obtenidos: mapas en formato de imagen y shapefile.

G. Centro Nacional de Información Geográfica. (16 de diciembre de 2020). Centro de descargas. Instituto Geográfico Nacional. Recuperado el 17 de diciembre de 2020 en http://centrodedescargas.cnig.es/CentroDescargas/index.jsp. Datos obtenidos: cartografía en formatos SIG, shapefile, ráster, documentos georreferenciados (mapas topográficos, planos, archivos sobre infraestructuras, límites administrativos y red hidrológica), Nomenclátor Geográfico y mapas Corine-Land Cover.

H. Observación del Territorio. (2020). Instituto Geográfico Nacional. http://centrodedescargas.cnig.es/CentroDescargas/index.jsp. Datos obtenidos: fotografías aéreas desde 1956 y ortofotografías recientes.

A. Instituto Nacional de Estadística. (23 de diciembre de 2020). https://www.ine.es/. Datos de censos, padrones, nomenclátores demográficos y Contabilidad Nacional Anual de España.

I. Cartografía y SIG. (22 de diciembre de 2020). Descargas. Ministerio para la Transición Ecológica y el Reto Demográfico. Recuperado el 22 de diciembre de 2020 de https://www.miteco.gob.es/es/cartografia-y-sig/ide/descargas/default.aspx. Se han obtenido: mapas forestales de 1966 y actual, espacios protegidos y de interés, datos de regadíos y repoblaciones forestales.

J. Sistema de Información de Patrimonio Cultural Aragonés (2019) Patrimonio Inmaterial. Diputación de Huesca. Recuperado el 28 de noviembre de 2020 de http://www.sipca.es/censo/busqueda_oral_simple.html. Obtenidas imágenes de despoblados y archivos de audio grabados a personas que vivieron en los años en los que se produjeron los procesos de despoblación en la provincia de Huesca.

\subsection{Paisaje, patrimonio cultural y despoblación}

Los contenidos se encuentran, organizados en capítulos en un "Hub" con ese título, que se encuentra en esta URL: http://bit.ly/TMudejar. Cada capítulo es un Story Map en el que se abordan contenidos y tareas de una forma ordenada. Sus títulos y los contenidos y problemas planteados son: 


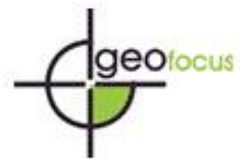

Velilla Gil, J., Guallart Moreno, C., Laguna Marín-Yaseli, M. (2021). Materiales educativos para trabajar conceptos sobre desarrollo sostenible en las aulas de educación secundaria. GeoFocus (Artículos), Revista Internacional de Ciencia y Tecnología de la Información Geográfica, 27, 55-93. http://dx.doi.org/10.21138/GF.676

\subsubsection{Paisaje, patrimonio cultural y despoblación.}

Se localiza en: https://arcg.is/1C8Xr0. Se trata de una introducción en la que se incluye una relación de los tipos de materiales que se ofrecen: Story Maps, aplicaciones y visores, y una breve explicación sobre su uso. Se complementa con unos "vídeos tutoriales", que se ofrecen al final del Hub, y que, en menos de cinco minutos, explican cómo utilizar cada una de las herramientas que aparecen a lo largo de los diferentes Story Maps.

\subsubsection{Patrimonio cultural y natural.}

Se localiza en: https://arcg.is/0K8m4a. Explica qué es patrimonio, qué diferencias hay entre patrimonio natural y cultural, qué es "Patrimonio de la Humanidad" y qué diferencias hay entre el Patrimonio Mundial y los Bienes de Interés Cultural. Posteriormente se trata el tema del patrimonio cultural aragonés, ofreciendo una actividad para reconocer los cuatro conjuntos de bienes que están en la Lista del Patrimonio Mundial. Por último, se explican las normas que protegen el patrimonio aragonés.

\subsubsection{Localización y medio físico de Territorio Mudéjar.}

En: https://arcg.is/Sm5LS. Comienza explicando qué es Territorio Mudéjar y que municipios formaban parte de él en 2019. Luego representa cartográficamente los asentamientos mudéjares aragoneses y pasa a analizar cómo es su medio físico: el relieve, la red hidrográfica, la vegetación y los usos del suelo.

\subsubsection{Orígenes del mudéjar.}

En: https://arcg.is/0Pyraa. Comienza con una explicación de la etimología del término mudéjar, relacionándola con las características de los elementos que definen el estilo de la arquitectura mudéjar. Luego plantea tareas para reconocer el origen histórico de los asentamientos mudéjares aragoneses, su localización, las formas de vida en esos asentamientos; e introduce los términos reconquista, capitulaciones y moriscos. Finaliza con una tarea que relaciona la distribución de la toponimia de origen mudéjar y la localización de la arquitectura mudéjar en Aragón.

\subsubsection{La arquitectura mudéjar en Aragón.}

En: https://arcg.is/1eeWzT1. A partir de la definición de arquitectura mudéjar, pasa a trabajar con imágenes los tipos de iglesias, de torres campanario, de claustros, de cimborrios y de techumbres de ese estilo arquitectónico. Acaba con una actividad de localización de los edificios mudéjares que quedan en pie, de sus funciones y de los elementos arquitectónicos que caracterizan a cada uno de ellos.

\subsubsection{Aprendiendo de Mahoma Ramí.}

Localizado en: https://arcg.is/1rmPia. Es un juego de roles diseñado a partir de estrategias de gamificación. El argumento del juego parte del personaje Mahoma Ramí, famoso alarife que vivió en el siglo $\mathrm{XV}$, con el que muchos jóvenes van a querer aprender, para trabajar con él, el oficio de la construcción. Para seleccionar a sus ayudantes, el alarife les plantea una serie de 


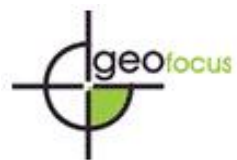

Velilla Gil, J., Guallart Moreno, C., Laguna Marín-Yaseli, M. (2021). Materiales educativos para trabajar conceptos sobre desarrollo sostenible en las aulas de educación secundaria. GeoFocus (Artículos), Revista Internacional de Ciencia y Tecnología de la Información Geográfica, 27, 55-93. http://dx.doi.org/10.21138/GF.676

retos que tienen que ver con el reconocimiento de elementos arquitectónicos en la ciudad de Zaragoza y sus localidades próximas. El que acabe con éxito las tareas antes resultará vencedor.

\subsubsection{Las ciudades medievales.}

En: https://arcg.is/0iXmKT. Tras unas explicaciones sucintas sobre la morfología, la tipología, el tamaño y el rango de las ciudades medievales, se ofrece una tarea, a partir de una aplicación, para localizar ciudades que conservan el trazado y restos urbanos y arquitectónicos medievales, localizarlas y describirlas a partir de su tamaño demográfico y de sus elementos urbanos (murallas, puertas, edificios singulares y barrios urbanos).

\subsubsection{La literatura de los mudéjares.}

En: https://arcg.is/1nOj8L0. Parte de la diferenciación de literatura popular y culta. Luego, en un mapa, muestra la evolución territorial de las lenguas en la península Ibérica, para llegar a explicar y mostrar que fue la aljamía y la literatura aljamiada. Muestra, como ejemplo, el poema de Yusuf y plantea unas tareas de construcción por parte de los alumnos de un texto literario aljamiado a partir de ese poema. Ese texto se puede realizar siguiendo las indicaciones que se van dando en el Story Map o en la aplicación que lo cierra.

\subsubsection{Patrimonio natural.}

En: https://arcg.is/10v90q. Se inicia con la descripción de los ríos que discurren por Territorio Mudéjar, para pasar a una aplicación en la que los alumnos trabajan sobre la red hidrológica de ese territorio y las características de los cursos, cauces y riberas de esos ríos. También se introducen los temas de la vegetación, diferenciando potencial y real, y de la protección medioambiental, a partir de los Lugares de Importancia Comunitaria (LIC). La última tarea es un trabajo de campo en el que se utiliza una aplicación (Collector for ArcGIS) en el teléfono móvil de los alumnos, que, distribuidos en grupos, realizan con esa aplicación la recogida de datos (fotografías y comentarios sobre características y estado físico) de los cursos de agua y la vegetación de los espacios próximos a la localidad en la que residen y a aquella en la que se ubica el centro escolar en el que estudian. Conforme esos datos lleguen a la geodatabase de la aplicación, se irán elaborando dos mapas (hidrología y vegetación). La fauna se trabaja a partir de una aplicación en la que se plantea una estrategia para avistar aves y estudiar su comportamiento, grabando un vídeo con esa información y luego difundiéndolo en el centro en el que cursan sus estudios.

\subsubsection{Territorio Mudéjar. Población.}

En: https://arcg.is/Ozfza. Analiza el reparto de la población, crecimiento y envejecimiento demográficos en los municipios de Territorio Mudéjar, y compara esas cifras con las de los que no pertenecen a esa asociación, pero tienen Bienes de Interés Cultural, y con las del resto de Aragón. Enlaza con el siguiente capítulo: "factores del reparto de la población".

\subsubsection{Factores del reparto de la población.}

En: https://arcg.is/0iLrzS. Enlaza con el capítulo anterior. Parte del mapa en el que se representa el desigual reparto de la población en Territorio Mudéjar y en Aragón y, con el fin de identificar los factores que lo han producido, pasa a relacionarlo con el relieve, la red fluvial, los 


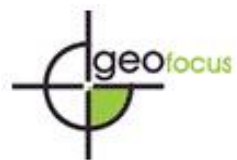

Velilla Gil, J., Guallart Moreno, C., Laguna Marín-Yaseli, M. (2021). Materiales educativos para trabajar conceptos sobre desarrollo sostenible en las aulas de educación secundaria. GeoFocus (Artículos), Revista Internacional de Ciencia y Tecnología de la Información Geográfica, 27, 55-93. http://dx.doi.org/10.21138/GF.676

diferentes usos del suelo, la red de comunicaciones por carretera, el acceso a los servicios y la proximidad a municipios con cinco mil o más habitantes.

\subsubsection{Desarrollo rural.}

En: https://arcg.is/1bvGWH. Comienza con la caracterización de los espacios rurales y de las diferencias que tienen con los urbanos. A continuación, se aborda la problemática de los primeros a partir de la dotación de servicios, los procesos de despoblación, la rentabilidad comparada de las actividades agrarias y los ingresos medios por habitante. Desde la identificación de esas realidades y la comprensión de las desigualdades territoriales en el reparto de las mismas, se trabaja sobre las políticas de desarrollo rural y los procesos asociativos que se están llevando a cabo en Aragón y, más en concreto, en los municipios de Territorio Mudéjar, con el fin de generar iniciativas y participar en la toma de decisiones. A partir de las opiniones de personas que trabajan en desarrollo rural, se deduce la importancia de una correcta valoración del patrimonio cultural, artístico, histórico, natural, etc. de las localidades rurales con el fin de generar entre sus habitantes un sentimiento identitario que implemente una actitud de búsqueda de actuaciones y recursos que hagan sostenible la vida en esos municipios. Por último, siguiendo una estrategia didáctica de "aprendizaje-servicio", se plantea el proyecto de elaborar un folleto turístico sobre la localidad en la que residen los alumnos. Se muestran modelos de folletos de Calatayud, La Almunia de Doña Godina y Aínsa, se identifican las informaciones que contienen y cómo se presentan, y se ofrece una aplicación SIG para producir la cartografía necesaria para comunicar esas informaciones.

Después de estos doce capítulos, se pasa a dos secciones que tienen la finalidad de facilitar el uso de estos materiales si los usuarios optan por trabajar sólo con algunas actividades realizadas con "aplicaciones":

1. Mapas interactivos es un listado desde el que acceder directamente a todas las aplicaciones SIG que se han utilizado en los diferentes capítulos de "paisaje, patrimonio cultural y despoblación".

2. Visores de proyectos ofrece los enlaces a las cuatro actividades de recogida de información georreferenciada que se han utilizado para construir mapas sobre diferentes temas de forma "cooperativa", usando software SIG (Collector for ArcGIS).

3.2.13. Las fuentes de las que se han obtenido los datos, imágenes, recursos, etc., además de las citadas en los propios materiales, han sido:

B. Atlas Nacional de España. (2020). Instituto Geográfico Nacional. http://www.ign.es/web/ign/portal/ane-area-ane. Datos obtenidos: mapas en formato de imagen y shapefile.

C. Centro Nacional de Información Geográfica. 16 de diciembre de 2020). Centro de descargas. Instituto Geográfico Nacional. Recuperado el 17 de diciembre de 2020 de http://centrodedescargas.cnig.es/CentroDescargas/index.jsp. Datos obtenidos: cartografía en formatos SIG, shapefile, ráster, documentos georreferenciados (mapas topográficos, planos, archivos sobre infraestructuras, límites administrativos y red hidrológica.

D. Observación del Territorio. (2020). Instituto Geográfico Nacional. http://centrodedescargas.cnig.es/CentroDescargas/index.jsp. Datos obtenidos: fotografías aéreas desde 1956 y ortofotografías recientes. 
Velilla Gil, J., Guallart Moreno, C., Laguna Marín-Yaseli, M. (2021). Materiales educativos para trabajar conceptos sobre desarrollo sostenible en las aulas de educación secundaria. GeoFocus (Artículos), Revista Internacional de Ciencia y Tecnología de la Información Geográfica, 27, 55-93. http://dx.doi.org/10.21138/GF.676

E. Nomenclátor Geográfico de Aragón. (octubre de 2020). Infraestructura de Datos Espaciales de Aragón. Recuperado en https://idearagon.aragon.es/toponimia/. Datos obtenidos: conjunto de nombres oficiales georreferenciados sobre cartografía topográfica a escala 1:10.000 o mayores. Las denominaciones incluidas en el Nomenclátor Geográfico de Aragón son de uso obligado en la cartografía oficial elaborada o informada por el Instituto Geográfico de Aragón o por el resto de las administraciones de la Comunidad Autónoma.

F. Infraestructura de Datos Espaciales de España. (2 de diciembre de 2020). Buscador de datos y servicios geográficos. Ministerio de Transportes, Movilidad y Agenda Urbana. https://www.idee.es/es_ES/web/guest/inicio. Se ha obtenido acceso a los centros descarga de datos de las CCAA, en concreto de Aragón (Aragón Open data, IDE de Aragón) y direcciones de los Servicios Web (OGC, INSPIRE) disponibles).

G. Instituto Nacional de Estadística. (23 de diciembre de 2020). https://www.ine.es/. Datos de censos, padrones, nomenclátores demográficos y Contabilidad Nacional Anual de España.

H. Cartografía y SIG. (22 de diciembre de 2020). Descargas. Ministerio para la Transición Ecológica y el Reto Demográfico. Recuperado el 22 de diciembre de 2020 de https://www.miteco.gob.es/es/cartografia-y-sig/ide/descargas/default.aspx. Se han obtenido: mapas forestales de 1966 y actual, espacios protegidos y de interés, datos de flora y fauna en España, y de ecosistemas.

I. Tolosa, J.A. (s.f.). https://www.aragonmudejar.com/index.htm. Datos obtenidos: localización y características de bienes mudéjares en Aragón

J. Dirección General de Cultura y Patrimonio del Gobierno de Aragón. (22 de diciembre de 2020). Cultura de Aragón. Departamento de Educación, Cultura y Deporte del Gobierno de Aragón. Recuperado el 22 de diciembre de 2020 de http://www.patrimonioculturaldearagon.es/. Acceso a datos sobre el patrimonio cultural de Aragón formado por Bienes Culturales que representan la identidad histórica, artística, cultural y natural de la Comunidad.

K. Territorio Mudéjar. (9 de diciembre de 2020). https://www.territoriomudejar.es/. Datos sobre los municipios que forman parte de esa asociación.

L. Aragón Open Data. (24 de julio de 2020). Banco de datos. Instituto Aragonés de Estadística del Gobierno de Aragón. Recuperado el 1 de diciembre de 2020 de https://opendata.aragon.es/datos/catalogo. Obtenidas: localización y catalogación de los Bienes de Interés Cultural aragoneses, adaptados a partir de la obra de Alcalá et al. (2005).

3.3. El cambio climático y sus repercusiones

Los materiales se presentan (en: https://arcg.is/0W588a) en un Story Map, clasificados en siete capítulos, a los que se puede acceder desde las pestañas en las que se indica su temática:

\subsubsection{Empezamos.}

En https://arcg.is/0W588a. Está en la primera página del Story Map. Es el primer grupo y se dedica a trabajar sobre los conceptos básicos que son necesarios para, luego, trabajar con el resto de los materiales. Se abordan los conceptos de cambio climático, causas del mismo, Gases 


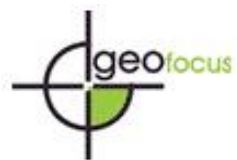

Velilla Gil, J., Guallart Moreno, C., Laguna Marín-Yaseli, M. (2021). Materiales educativos para trabajar conceptos sobre desarrollo sostenible en las aulas de educación secundaria. GeoFocus (Artículos), Revista Internacional de Ciencia y Tecnología de la Información Geográfica, 27, 55-93. http://dx.doi.org/10.21138/GF.676

de Efecto Invernadero (GEI) y cambios en las temperaturas ocurridos antes y estudiados por la Paleoclimatología.

\subsubsection{Las temperaturas.}

En: https://arcg.is/4TzX4. En este capítulo, una aplicación se utiliza para analizar la distribución de las anomalías térmicas (cambio en las temperaturas medias anuales con respecto a las medias del período 1986-2005) que el IPCC prevé en cuatro posibles escenarios para 2040. La denominación de estos escenarios se ha adaptado a la edad y nivel formativo de los alumnos a los que van destinados estos materiales. Así, el escenario 2.6 es aquel en el que la concentración de GEI en la atmósfera comienza a disminuir antes de 2100 y las emisiones de los mismos son 0 alrededor de 2070; el escenario 4.5 prevé una estabilización de las emisiones de GEI en niveles medio-bajos a partir de 2100; el escenario 6 prevé esa estabilización en niveles medios en las mismas fechas; y el escenario 8.5 se basa en la continuidad de las emisiones contaminantes con GEI después de 2100.

\subsubsection{Las precipitaciones.}

En: https://arcg.is/1SbLWa. Ofrece una aplicación para analizar distribución de la anomalía en la cantidad de precipitaciones anuales (litros $/ \mathrm{m}^{2}$ ) en $\operatorname{los}$ cuatro escenarios antedichos y en la intensidad (litro/ $\mathrm{m}^{2} /$ segundo) de las mismas, en los meses de mayo y de octubre, en un escenario 2.6. Incluye también otras capas para poder evaluar los daños que esas anomalías pueden causar: desiertos, formas de relieve y frecuencia e intensidad de los desastres naturales asociado a las inundaciones y a los ciclones y tornados. Por último, ofrece una capa sobre la distribución mundial de las precipitaciones anuales en la actualidad.

\subsubsection{Impactos en los océanos y la población.}

En: https://arcg.is/0qqW9C0. Es una aplicación para relacionar la distribución de las anomalías térmicas, en los cuatro escenarios, con la evolución de la superficie oceánica cubierta por el hielo en el hemisferio norte desde 1979, los glaciares en el mundo, la superficie ocupada por las aguas del mar si el nivel de este asciende cinco metros, las grandes ciudades del mundo y el reparto de la población, en 2020 (representado como número de habitantes en cada cuadrado de una rejilla de cuadrados que cubre todas las superficies emergidas). Se trabaja también con información "añadida" desde internet sobre las corrientes marinas, para identificar y comprender los cambios que se están produciendo en ellas y las consecuencias que tienen para la vida en el mar.

\subsubsection{Impactos en la alimentación y la población.}

En: https://arcg.is/09eGru. Relaciona la distribución de la anomalía térmica en 2040 (en los cuatro escenarios previstos) y una capa sobre la distribución de los espacios que sufren frecuentes e intensas sequías. El objetivo es evaluar las consecuencias de esos aumentos de las temperaturas en zonas que ya sufren esos desastres naturales o que están muy próximas a hacerlo. Identificados y localizados los espacios en los que el aumento de las temperaturas eleva el riesgo de sequía, se relacionan con la distribución de la malnutrición infantil, de los usos de los suelos en 2015 con un mapa Corine Land Cover (EEA (21-12-2020) adaptado para uso educativo y con el reparto de la población mundial 2020. El objetivo de esas relaciones es reconocer que el calentamiento global tiene consecuencias más graves en espacios áridos y 


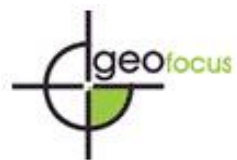

Velilla Gil, J., Guallart Moreno, C., Laguna Marín-Yaseli, M. (2021). Materiales educativos para trabajar conceptos sobre desarrollo sostenible en las aulas de educación secundaria. GeoFocus (Artículos), Revista Internacional de Ciencia y Tecnología de la Información Geográfica, 27, 55-93. http://dx.doi.org/10.21138/GF.676

semiáridos, con bajos ingresos y con aprovechamientos del suelo relacionados con agricultura de secano, vegetación natural de bosques poco densos, matorral, herbáceos o vegetación de zonas áridas o semiáridas.

\subsubsection{Cambio climático y migraciones.}

En: https://arcg.is/DHuTj. Es una aplicación orientada a recapitular lo trabajado hasta ahora: incluye las capas sobre reparto de anomalías térmicas y en la intensidad y cantidad de las precipitaciones, y las de los desastres naturales (sequías, inundaciones, ciclones y tornados). A partir de los aprendizajes ya realizados con las interrelaciones que hay entre esos elementos, se plantea la relación entre estos y los movimientos migratorios, representados con cartografía de número total de emigrantes y de inmigrantes, por países, entre 1990 y 2019, a la que se "añade" desde internet la de países según su grado de desarrollo. A partir de la herramienta "indicaciones" se guía al alumno a concluir que los movimientos migratorios actuales mantienen relación con el cambio climático, pero no una relación directa, sino a través de la ponderación del nivel de desarrollo y riqueza que favorece o dificulta las respuestas al mismo.

\subsubsection{La lucha contra el cambio climático.}

Se encuentra en la página final del Story Map (https://arcg.is/0W588a), y aborda el proceso, iniciado en 1992, con el Convenio Marco de Naciones Unidas sobre Cambio Climático, que cinco años más tarde dio lugar al Protocolo de Kioto, y que dura hasta la actualidad, cuando se están intentando implementar los acuerdos de la Cumbre de París, en 2015.

3.3.8. Las fuentes de las que se han obtenido los datos para construir la cartografía de estos materiales educativos, además de los recursos no cartográficos, que llevan su fuente visible, son:

A. Natural Earth. (2020). Recuperado el 18 de noviembre de https://www.naturalearthdata.com/. Ofrece de forma pública y gratuita material cartográfico descargable en formatos utilizados en los SIG. Se han utilizado los archivos shapefile de países del mundo en 2020 y los de coordenadas geográficas.

B. The Intergovernmental Panel on Climate Change. (2015). Climate Change 2014: Synthesis Report. Contribution of Working Groups I, II and III to the Fifth Assessment Report of the Intergovernmental Panel on Climate Change. https://www.ipcc.ch/report/ar5/syr/. Datos sobre los escenarios de forzamiento radiativo previstos por el IPCC y sus consecuencias sobre las anomalías térmicas y en las precipitaciones (total anual e intensidad mensual).

C. The Intergovernmental Panel on Climate Change. (2012). Managing the Risks of Extreme Events and Disasters to Advance Climate Change Adaptation. https://www.ipcc.ch/report/managing-the-risks-of-extreme-events-and-disasters-toadvance-climate-change-adaptation/. Datos sobre gestión de los riesgos de fenómenos meteorológicos extremos y desastres para mejorar la adaptación al cambio climático.

D. University Corporation for Atmospheric Research. (2020). Climate Change Scenarios. https://gisclimatechange.ucar.edu/. Ofrece de forma pública y gratuita los datos del último informe del IPCC en formatos SIG. 
Velilla Gil, J., Guallart Moreno, C., Laguna Marín-Yaseli, M. (2021). Materiales educativos para trabajar conceptos sobre desarrollo sostenible en las aulas de educación secundaria. GeoFocus (Artículos), Revista Internacional de Ciencia y Tecnología de la Información Geográfica, 27, 55-93. http://dx.doi.org/10.21138/GF.676

E. NASA's Earth Observing System Data and Information System. (2020), Socioeconomic Data and Applications Center. Columbia University. New York. https://sedac.ciesin.columbia.edu/. Servicios WMS-OGC con datos sobre población, desastres naturales, condiciones sociales y hábitats a escala mundial.

F. World Bank. (2020), Data Bank. https://databank.worldbank.org/reports.aspx? source=2\&series=SI.POV.DDAY\&countr $\mathrm{y}=\mathrm{WLD \#}$. Datos sobre población, ingresos, nivel de desarrollo, contaminación atmosférica, etc. a escala mundial, por países y por agrupaciones de los mismos.

G. United Nations Conference on Trade and Development (2020). Handbook of Statistics. https://unctadstat.unctad.org/wds/ReportFolders/reportFolders.aspx?sCS_ChosenLang= en 2020. Datos sobre cuentas económicas, nivel de desarrollo, población, etc. a escala mundial, por países y por agregados (países según niveles de desarrollo, organizaciones internacionales, continentes y regiones $\mathrm{UN}$ ).

\section{4. ¿Cómo se presentan los materiales?}

Los materiales, como ya se ha indicado en varias ocasiones, son el resultado de la utilización de software de los SIG, concretamente de ArcGIS Online, que ha cedido gratuitamente ESRI España para estos proyectos. Esta utilización ha tenido tres formas:

1. La elaboración de los contenidos a partir de la investigación y búsqueda de los datos necesarios para construirlos. Lo que ha tenido como consecuencia que esos datos y esos contenidos hayan adoptado mayoritariamente formatos cartográficos.

2. La elaboración de herramientas, generalmente aplicaciones, para que los usuariosalumnos puedan utilizar herramientas adecuadas para resolver las tareas que se les plantean, a partir de las estrategias didácticas (aprendizajes en competencias, ABP, etc.) que están en el origen de los itinerarios formativos que se ofrecen. De estas estrategias y de los objetivos que persiguen se ha tratado en el apartado 2.1.

3. La comunicación de los contenidos y de las tareas. Como se ha podido observar en la descripción de los materiales, se ha mantenido la unidad de cada grupo de contenidos, de forma que el acceso a cada uno de esos grupos es a partir de su Hub o su Story Map (este formato sólo para el tema del cambio climático, que, de momento, tiene menos contenidos y tareas que los otros temas), desde los que se despliegan los capítulos de los que se compone cada grupo de contenidos. Cada uno de estos capítulos se ofrece como un Story Map, en el que se articulan contenidos y tareas, en los que predomina el trabajo con cartografía, fundamentalmente a partir de la utilización de aplicaciones, pero cuando se ha visto que es más eficiente, también de otros formatos, como archivos de audio, diagramas, tablas de datos, imágenes, infografías, vídeos, etc.

\section{Experimentación de los resultados}

Como se ha comentado en la introducción de este artículo, la experimentación no ha concluido y lo que se ha podido ir haciendo ha sido poco exhaustivo, aunque ha servido para ir modificando algunos aspectos de los materiales para que funcionasen mejor (son materiales online con una cierta complejidad tecnológica) y para que fuesen más eficientes al generar aprendizajes. La idea originaria era experimentarlos con una muestra de alumnos suficiente para obtener resultados consistentes y con un cierto grado de objetividad, pero las circunstancias han conducido a que la muestra se redujese a la experimentación, durante catorce horas lectivas, en 


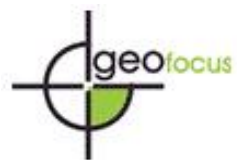

Velilla Gil, J., Guallart Moreno, C., Laguna Marín-Yaseli, M. (2021). Materiales educativos para trabajar conceptos sobre desarrollo sostenible en las aulas de educación secundaria. GeoFocus (Artículos), Revista Internacional de Ciencia y Tecnología de la Información Geográfica, 27, 55-93. http://dx.doi.org/10.21138/GF.676

cuatro centros educativos, con ciento ochenta y cuatro alumnos de tercero de ESO, en dos grupos de cada centro. Esta muestra se logró a partir del ofrecimiento de sus profesores, miembros del antedicho grupo de trabajo sobre utilidad de los SIG para llevar a cabo procesos de enseñanza-aprendizaje competenciales. Lo que ya sesgaba algo los resultados dado que esos profesores ya partían de la idea preconcebida de la utilidad de la herramienta elegida para elaborar los materiales.

La duración de la experimentación tampoco ha permitido sacar conclusiones concluyentes, ya que a esos catorce períodos lectivos (de cincuenta y cinco minutos) hay que restarle una o dos horas iniciales para la presentación de los materiales y para la familiarización de los alumnos con la utilización y manejo de los mismos, especialmente con las aplicaciones elaboradas con SIG.

Hay que indicar, no obstante, que esas circunstancias no han obedecido a dejadez por parte de quienes han elaborado los materiales o de quienes se han ofrecido voluntariamente para experimentarlos en las aulas con sus alumnos, sino que son el resultado del calendario escolar y de las circunstancias. El calendario escolar tiene más días lectivos en el primer trimestre y, además, no lleva carga lectiva de tareas acumuladas, como son tareas y pruebas de recuperación, etc. y parecía el mejor para llevar a cabo la experimentación, pero este primer trimestre ya estaba avanzado cuando los materiales estuvieron listos para poder ser experimentados y hubo que utilizar el segundo trimestre. Por otro lado, la realización de actividades extracurriculares, como la experimentación de estos materiales, requiere de la autorización de la administración educativa, de las familias de los alumnos, de los equipos directivos, de los claustros de profesores y de los alumnos que la van a realizar. Todo ello requiere tiempo y dificulta que ese tipo de actividades se pueda realizar en las primeras semanas del curso. En el curso siguiente, 2019-2020, el estallido de la COVID-19 hizo inviable la experimentación.

Para intentar paliar los efectos distorsionadores de las circunstancias que rodearon la experimentación, se planteó evaluar los materiales a partir del grado en la adquisición, por parte de los alumnos, de las competencias relacionadas con el saber geográfico y de las de carácter general (Anexo 1), que se planteaban como objetivo para los mismos (ver apartado 2.1.). Para dar fiabilidad a esos datos, los equipos evaluadores de cada grupo de alumnos, utilizando esos mismos criterios, evaluaron cómo había sido el grado en la adquisición de esas competencias o destrezas en el primer trimestre, para poderlo comparar con el que se estimó como resultado de la utilización de los materiales. A pesar de que los datos que se obtuvieron presentaban, al menos aparentemente, cierta homogeneidad y que los equipos evaluadores pusieron empeño en obtener datos con la mayor objetividad, se observó que era difícil evaluar la adquisición de competencias (restaba cierta credibilidad) cuando los procesos de enseñanza aprendizaje llevados a cabo en el primer trimestre no se habían realizado persiguiendo exactamente objetivos competenciales, ni utilizando el mismo tipo de herramientas didácticas.

Se introdujo también otro criterio que sirviese para evaluar los materiales escolares y que añadiese consistencia a los resultados. Vistos los rendimientos obtenidos en la primera evaluación y en la evaluación predictiva inicial, los objetivos y los criterios de evaluación y de calificación marcados en las programaciones didácticas, pareció adecuado utilizar, de forma totalmente anónima y privada, una clasificación de los alumnos en dos grupos: aquellos que obtenían aprendizajes similares o superiores a lo esperado y aquellos otros que los obtenían inferiores. En la evaluación de los materiales se estimó cómo el trabajo con los mismos afectaba a un grupo y a otro. 


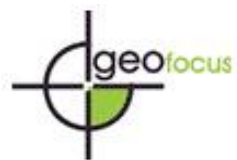

Velilla Gil, J., Guallart Moreno, C., Laguna Marín-Yaseli, M. (2021). Materiales educativos para trabajar conceptos sobre desarrollo sostenible en las aulas de educación secundaria. GeoFocus (Artículos), Revista Internacional de Ciencia y Tecnología de la Información Geográfica, 27, 55-93. http://dx.doi.org/10.21138/GF.676

Por último, con el fin de adecuar la experimentación a las preferencias de profesores y alumnos por unos u otros temas, se ofreció a cada centro escolar elegir el grupo temático que quería experimentar, partiendo de la idea de que los tres bloques de contenidos ("procesos de despoblación en Aragón", "paisaje, patrimonio cultural y patrimonio" y "cambio climático y sus repercusiones") estaban elaborados a partir de las mismas estrategias didácticas, con las mismas herramientas y trataban temas diferentes, pero íntimamente relacionados a partir del concepto de desarrollo sostenible, se pensó que esa posibilidad de optar por uno u otro tema no iba a añadir heterogeneidad a los resultados de los aprendizajes, ya que no se valoraba lo que se sabía de un contenido u otro, sino las destrezas o competencias adquiridas.

Los resultados, con las salvedades devenidas de las circunstancias en las que se realizó la experimentación y de las formas de evaluar los aprendizajes adquiridos, fueron positivos: la adquisición de las destrezas, tanto geográficas como generales, fue superior con el trabajo con los materiales presentados, especialmente con aquellos alumnos que en la primera evaluación habían obtenido resultados de aprendizaje inferiores a lo esperado.

Del conjunto de competencias planteadas como "transversales", las que peores resultados obtuvieron fueron: "utiliza conceptos y herramientas de diferentes materias para resolver problemas geográficos", "se comunica de forma lógica y ordenada", "evalúa críticamente sus planteamientos y los de sus compañeros", "identifica y comprende su posición en el grupo" y "evalúa las ventajas e inconvenientes de los diferentes formatos en los que se puede presentar la información", que suponemos que o están mal trabajadas en los materiales educativos o son las que tienen menor tratamiento en las estrategias didácticas convencionales, haciendo que los aprendizajes posteriores sean más costosos.

\section{Conclusiones}

Parece necesario llevar a cabo una nueva experimentación para poder obtener resultados concluyentes y objetivos. Está deberá tener una muestra de mayor tamaño (al menos doce centros educativos) y que tenga alumnos de diferentes contextos sociales y culturales. Para poder evaluar objetivamente la experimentación, debe tener una mayor duración y, así, obtener la certeza de que los aprendizajes adquiridos se deben a los materiales experimentados. Por otro lado, es muy importante que los profesores que van a experimentar los materiales conozcan al comienzo del curso escolar los materiales, las estrategias didácticas en las que se basan, las herramientas utilizadas para su elaboración y los contenidos que abordan y cómo lo hacen, para evitar que los procesos de enseñanza-aprendizaje realizados previamente a la experimentación sean demasiado diferentes a los de ésta y, por ello, la evaluación de los logros con los materiales no sea concluyente. Por último, todos los grupos de alumnos de todos los centros que participen en la experimentación deben trabajar sobre los mismos temas, contenidos y tareas, para asegurar un grado elevado de homogeneidad que otorgue valor a las conclusiones que se obtengan.

Por otra parte, parece pertinente ampliar los materiales sobre cambio climático, bien incluyendo los actuales en un bloque más amplio sobre sostenibilidad medioambiental, bien trabajando más las fuentes contaminantes y las consecuencias del cambio climático.

Por último, parece conveniente intentar experimentar estos materiales en otras materias o asignaturas, como Biología, Ciencias de la Tierra, Historia, Ciudadanía o Ética, etc. que no tengan sólo contenidos geográficos, pero en las que esté presente el concepto troncal de la sostenibilidad de la acción antrópica y el método de utilizar la distribución espacial para analizar el contenido o elemento que se está analizando. 
Velilla Gil, J., Guallart Moreno, C., Laguna Marín-Yaseli, M. (2021). Materiales educativos para trabajar conceptos sobre desarrollo sostenible en las aulas de educación secundaria. GeoFocus (Artículos), Revista Internacional de Ciencia y Tecnología de la Información Geográfica, 27, 55-93. http://dx.doi.org/10.21138/GF.676

\section{Referencias bibliográficas}

Álvarez Suárez, P. y Vega Marcote, P. (2009). Actitudes ambientales y conductas sostenibles. Implicaciones para la educación ambiental. Revista de Psicodidáctica, 14(2), 245-260.

Baker, T.R., Battersby, S., Bednarz, S.W., Bodzin, A.M., Kolvoord, B., Moore, S., Sinton, D. y Uttal, D. (2015). A Research Agenda for Geospatial Technologies and Learning. Journal of Geography, $114(3)$

118-130. https://www.tandfonline.com/doi/full/10.1080/00221341.2014.950684?scroll=top\&needAccess $=$ true.

Ballester, M.G. y Sánchez Santamaría, J. (2010). Programar y evaluar por competencias en educación primaria. Ediciones de la Universidad de Castilla-La Mancha.

Barbas Coslado, A., Goig Martínez, M., López-Jurado Puig, M., Román González, M., Santiago Campión, R., Santoveña Casal, S., Tasende Maña, B. y Trillo Miravalles, M.P. (2014). La educación en la sociedad del conocimiento. En M. Goig Martínez (director), Formación del profesorado en la sociedad digital. Investigación, innovación y recursos didácticos. UNED.

Binkley, M., Erstad, O., Herman, J., Raizen, S., Ripley, M., Miller-Ricci and M., Rumble, M. (2012), "Defining Twenty-First Century Skills". En P. Griffin, B. McGaw y E. Care (eds.), Assessment and Teaching of $21^{s t}$ Century Skills (17-66). Springer.

Boulahrouz Lahmidi, M. (2018) Aprendizaje móvil y ciudadanía espacial en la educación para el desarrollo sostenible. Una propuesta para enseñanza de las ciencias sociales en educación secundaria obligatoria [Tesis doctoral, Universidad de Girona]. E-Archivo: http://hdl.handle.net/10803/620791

Buzo Sánchez, I. (2016). Aplicación de la Metodología del Aprendizaje Geográfico por descubrimiento basado en SIG en proyectos didácticos para $2^{\circ}$ de Bachillerato. En R. Sebastiá, y E.M. Tonda (eds.), La investigación e innovación en la enseñanza de la Geografía (pp. 477489). Publications de la Universitat d'Alacant.

Buzo Sánchez, I. (2017). De las TIG a las TAG: integrando la información en el aprendizaje Geográfico. En R. Sebastiá y E.M. Tonda (coord.), Enseñanza y aprendizaje de la geografía para el siglo XXI (pp. 175-200). Publications de la Universitat d'Alacant.

Castells Oliván, M. (2001), Internet y la sociedad en red [Lección inaugural del programa de doctorado sobre la sociedad de la información y el conocimiento, Universitat Oberta de Catalunya]. E-Archivo: https://docplayer.es/1295178-Internet-y-la-sociedad-red-manuelcastells.html.

Collantes, F. y Pinilla, V. (2011). Peaceful Surrender. The Depopulation of Rural Spain in the Twentieth Century. Cambridge Scholars Publishing.

Collazo Expósito L.M., Geli de Ciurana A.M., Benito Mundet, H. y Terradellas Piferrer, M.R. (29-31 de marzo, 2017). Formación del profesorado universitario, mediante procesos de cocreación, para incidir en la competencia transversal de la sostenibilidad [Comunicación en congreso]. Actas VII Congreso Universidad y Cooperación al Desarrollo: La Universidad y los Objetivos de Desarrollo Sostenible. Universidad Autónoma de Madrid. https://drive.google.com/file/d/0B7bN5Kzal-UBX0dXOTNmQIJISms/view.

Propuesta de Recomendación del Parlamento Europeo y del Consejo. 2005/022 1(COD), de 10 de noviembre de 2005, sobre las competencias clave para el aprendizaje permanente. (COM, 2005 , 


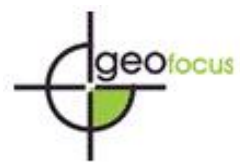

Velilla Gil, J., Guallart Moreno, C., Laguna Marín-Yaseli, M. (2021). Materiales educativos para trabajar conceptos sobre desarrollo sostenible en las aulas de educación secundaria. GeoFocus (Artículos), Revista Internacional de Ciencia y Tecnología de la Información Geográfica, 27, 55-93. http://dx.doi.org/10.21138/GF.676

http://www.europarl.europa.eu/meetdocs/2004_2009/documents/com/com_com(2005)0548_/co m_com(2005)0548_es.pdf.

Consejo Europeo de Lisboa. (23 y 24 de marzo de 2000). Conclusiones de la presidencia. https://www.europarl.europa.eu/summits/lis1_es.htm.

De Lázaro y Torres, M.L. y González González, M.J. (2005). "La utilidad de los sistemas de información geográfica para la enseñanza de la geografía”. Didáctica Geográfica, 7, pp. 105122.

De Miguel González, R. (2012). Análisis comparativo del currículum de Geografía en Educación Secundaria: revisión y propuestas didácticas. La educación geográfica digital, pp. 13-36. Grupo de didáctica de la Geografía (AGE).

De Miguel González, R. (2015). Del pensamiento espacial al conocimiento geográfico a través del aprendizaje activo con tecnologías de la información geográfica. Revista Geografía do Colégio Pedro II, 2(4), pp7-13.

De Miguel, R., De Lázaro, M.L., Velilla, J., Buzo, I., y Guallart, C. (1, de septiembre, 2016). Atlas Digital Escolar: Internet, Geografía y Educación. Ar@ cne. Revista electrónica de recursos en Internet sobre Geografía y Ciencias Sociales, pp. 212. Universitat de Barcelona. http://www.ub.edu/geocrit/aracne/aracne-212.pdf.

Ellis, E. C., Goldewijk, K., Siebert, S., Lightman, D, y Ramankutty, N. (2010). Anthropogenic transformation of the biomes, 1700 to 2000. Global Ecology and Biogeography 19(5), pp. 589606.

ESRI. (2020). ¿Qué es ArcGIS Hub? Recuperado el 18 de mayo de 2020 de https://doc.arcgis.com/es/hub/get-started/what-is-arcgis-hub-.htm.

European Commission. (2020). New Cohesion Policy. Recuperado el 23 de mayo de 2020 de https://ec.europa.eu/regional_policy/en/2021_2027/.

European Environment Agency [EEA] (21-12-2020). DiscoMap. Recuperado 21 de diciembre de 2020 de https://discomap.eea.europa.eu/Index/.

Ferreira, J. (2009). Unsettling orthodoxies: Education for the environment for sustainability. Environmental Education Research, 5(5), pp. 607-620.

García, J.M., Lasanta, T., Ruiz, P., Ortigosa, L., White, S., González, C., y Martí, C. (1996). Land use changes and sustainable development in mountain areas: A case study in the Spain Pyrenees. Landscape Ecology 11(5), pp.267-277.

Gardner, H. (1993). Frames of Mind. The Theory of Multiple Intelligences. Harper Collins Publisher, Inc.

Granados, J. (2011). La educación para la sostenibilidad en la enseñanza de la geografía. Un estudio de caso. Enseñanza de las Ciencias Sociales. Revista de Investigación, 10, pp. 28-41. Universidad de Barcelona.

Guallart, C., Velilla, J., Cuartero, N., Ferraz, M. F., Laguna, M., Ollero, A., Rodrigo, B. (2020). Propuesta de recursos didácticos en línea para trabajar patrimonio, despoblación y territorio en Educación Secundaria Obligatoria. Cuadernos de Geografía, 104, pp.153-176. Universidad de Valencia. 


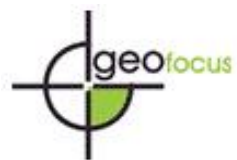

Velilla Gil, J., Guallart Moreno, C., Laguna Marín-Yaseli, M. (2021). Materiales educativos para trabajar conceptos sobre desarrollo sostenible en las aulas de educación secundaria. GeoFocus (Artículos), Revista Internacional de Ciencia y Tecnología de la Información Geográfica, 27, 55-93. http://dx.doi.org/10.21138/GF.676

Kerski, J.J. (2011). Sleepwalking into the Future. The Case for Spatial Analysis Throughout Education. En T. Jekel, A. Koller, K. Donert y R. Vogler (ed.), Learning with GI 2011 Implementing Digital Earth in Education, pp. 2-11. Wichmann Verlag.

Kerski, J.J. (2003). The implementation and Effectiveness of Geographic Information Systems Technology and Methods in Secondary Education. Journal of Geography, 102, pp. 128-137. National Council for Geographic Education.

Kolvoord, B. (2012). Integrating geospatial technologies and secondary student projects: the geospatial semester. Didáctica Geográfica, 13, pp. 57-67. Grupo de Didáctica de la Geografía (AGE).

Kyburz-Graber, R. (2013) Socioecological Approaches to Environmental Education and Research. En R.B. Stevenson, M. Brody, J. Dillon y A.E.J. Wals. (eds.), International Handbook of Research on Environmental Education. Routledge. https://www.routledgehandbooks.com/doi/10.4324/9780203813331.ch3.

Larmer, J. y Mergendoller, J.R. (2010). The Main Course, Not Dessert: How Are Students Reaching 21st. Century Goals? With 21st. Century Project Based Learning. Buck Institute for Education.

https://www.cisd.org/cms/lib6/TX01917765/Centricity/Domain/162/Main_Course.pdf.

Ley Orgánica 8/2013, de 9 de diciembre, para la mejora de la calidad educativa. BOE número 295, de 10 de diciembre de 2013, 97858 a 97921.

López Valdovinos, M (2001). Historia y Ciencias Sociales. Estrategias de enseñanza y aprendizaje. Pax México.

Marqués Graells, P. y Álvarez Cánovas, I. (2014). El currículo bimodal como marco metodológico para la evaluación: principios básicos y mejoras obtenidas en aprendizajes y rendimientos de los estudiantes. Educar, 50(1), pp. 149-166. Universidad Autónoma de Barcelona. https://www.raco.cat/index.php/Educar/article/view/287072.

Moreno Jiménez, A. (2013). Entendimiento y naturaleza de la cientificidad geotecnológica: una aproximación desde el pragmatismo epistemológico. Investigaciones Geográficas, 60, 05-36. Instituto Interuniversitario de Geografía. Universidad de Alicante.

Moreno-Latorre, E., Molins-Palanca, A., Padilla-Bautista, P. y Boisset-Castells, E. (5-8 de septiembre, 2017). El medio ambiente en las aulas de secundaria y bachillerato. Estudio de caso sobre la transversalidad en un centro educativo de Valencia [Comunicación en congreso]. $\mathrm{X}$ Congreso internacional sobre investigación en didáctica de las ciencias. Logros del pasado y retos del futuro, Sevilla. Enseñanza de las ciencias: revista de investigación y experiencias didácticas. Extra 0, pp. 3343-3349. https://dialnet.unirioja.es/servlet/articulo?codigo=6690520.

Naciones Unidas. (s.f.). Los Objetivos de Desarrollo Sostenible (ODS). https://www.un.org/sustainabledevelopment/es/objetivos-de-desarrollo-sostenible/.

Orden ECD/65/2015, de 21 de enero, por la que se describen las relaciones entre las competencias, los contenidos y los criterios de evaluación de la educación primaria, la educación secundaria obligatoria y el bachillerato (2015). BOE número 25 , de 29 de enero de 2015, 6986 a 7003).

Paniagua, A., Bryant, R. y Kizos, T. (ed.). (2012): The Political Ecology of Depopulation: Inequality, Landscape, and People. Zaragoza: CEDDAR. 


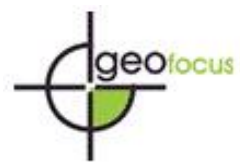

Velilla Gil, J., Guallart Moreno, C., Laguna Marín-Yaseli, M. (2021). Materiales educativos para trabajar conceptos sobre desarrollo sostenible en las aulas de educación secundaria. GeoFocus (Artículos), Revista Internacional de Ciencia y Tecnología de la Información Geográfica, 27, 55-93. http://dx.doi.org/10.21138/GF.676

Patton, J., (2014) User Story Mapping: Discover the Whole Story, Building the Right Product. O’Reilly Media, Inc.

Pérez Gómez, A.I. (2012). Educarse en la era digital. La escuela educativa. Madrid. Ed. Morata.

Prats, J. y Santacana, J. (2011) Por qué y para qué enseñar historia. En J. Prats (coord.) Didáctica de la Geografía y la Historia, pp.13-29. Ministerio de Educación, Cultura y Deporte, Secretaría General Técnica.

Programa de Naciones Unidas para el Desarrollo. (2020). Objetivos de Desarrollo Sostenible. https://www.undp.org/content/undp/es/home/sustainable-development-goals.html.

Puig Rovira, J.M., Gijón Casares, M., Martín García, X. y Rubio Serrano, L. (2011). Aprendizaje-servicio y Educación para la Ciudadanía. Revista de Educación, número extraordinario 2011. Educación, valores y democracia, pp. 45-67. Ministerio de Educación y Formación Profesional. http://www.educacionyfp.gob.es/revista-de-educacion/numeros-revistaeducacion/numeros-anteriores/2011/re2011/re2011-03.html.

Ramos, D.R. (coord.) (2010), Los Sistemas de Información Geográfica en la Educación Secundaria. Wanceulen Educación.

Roig-Vila, R. (2010) Innovación educativa e integración de las TIC. Un tándem necesario en la sociedad de la información. En R. Roig-Vila, y M. Fiorucci (coord.), Claves para la investigación en innovación y calidad educativas. La integración de las Tecnologías de la Información y la Comunicación y la Interculturalidad en las aulas. Marfil. http://www.edutic.ua.es/wp-content/uploads/2012/06/Claves-para-lainvestigacion_329_340-

Cap-26.pdf.

Sinton, D.S. y Lund, J.J. (2007). Understanding place: GIS and Mapping across the curriculum. ESRI. Inc.

Terradellas Piferrer, M.R., Collazo Expósito, L., Geli de Ciurana, A.M. y Benito Mundet, H. (2017): La competencia transversal de la sostenibilidad en la UdG: De la cumbre de Rio en la Co-creación, la IRRI y los ODS. En Co-creación, Innovación Responsable y Sostenibilidad [CD-ROM]. Girona. Càtedra RSU. Universidad de Girona/Documenta Universitària. https://www.udg.edu/ca/LinkClick.aspx?fileticket=CDTYbIAM2qk\%3d\&portalid=59.

Territorio Mudéjar. (2 de mayo de 2020). Estancias 2019: Patrimonio mudéjar y aprendizaje, el material pedagógico... https://www.territoriomudejar.es/patrimonio-mudejar-y-aprendizaje-elmaterial-pedagogico-conocer-el-patrimonio-para-valorarlo-e-idear-modelos-de-desarrollorural/.

Tomasello, M. (2008), Origins of human communication. Cambridge, Massachusetts. Massachusetts Institute of Technology (MIT).

UNESCOCAT (11 de julio de 2019). ABP para los ODS: sesión de formación con Bob Lenz [Video]. https://unescocat.org/es/portfolio-items/abp-para-los-ods-bob-lenz/.

United Nations, (2020). Climate Change. Recuperado el 3 de diciembre de 2020 de https://unfccc.int/process-and-meetings/the-paris-agreement/the-paris-agreement.

Varela Losada, M, Pérez Rodríguez, U, Álvarez Lires, J. y Álvarez Lires, M.M (2014). Desarrollo de Competencias Docentes a partir de Metodologías Participativas Aplicadas a la Educación Ambiental. Formación Universitaria, 7(6), pp. 27-36. 


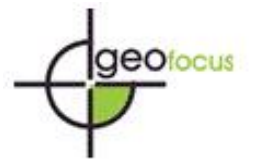

Velilla Gil, J., Guallart Moreno, C., Laguna Marín-Yaseli, M. (2021). Materiales educativos para trabajar conceptos sobre desarrollo sostenible en las aulas de educación secundaria. GeoFocus (Artículos), Revista Internacional de Ciencia y Tecnología de la Información Geográfica, 27, 55-93. http://dx.doi.org/10.21138/GF.676

Velásquez-Sarria, J.A. (2009). La trasversalidad como posibilidad curricular desde educación ambiental. Revista Latinoamericana de Estudios Educativos, 5, pp. 29-44.

Velilla Gil, J. y Laguna Marín-Yaseli, M. (2019). El problema de la despoblación en España y su tratamiento didáctico. Íber. Didáctica de las Ciencias Sociales. Geografía e Historia, 96, pp. 7-16.

Vergara Ramírez, J.J. (2015). Aprendo porque quiero. El Aprendizaje Basado en Proyectos $(A B P)$, paso a paso. Editorial SM. 
Velilla Gil, J., Guallart Moreno, C., Laguna Marín-Yaseli, M. (2021). Materiales educativos para trabajar conceptos sobre desarrollo sostenible en las aulas de educación secundaria. GeoFocus (Artículos), Revista Internacional de Ciencia y Tecnología de la Información Geográfica, 27, 55-93. http://dx.doi.org/10.21138/GF.676

\section{Anexo I}

Tabla 1. Rúbrica de evaluación general. Desarrollo de los procesos de aprendizaje

\begin{tabular}{|c|c|c|c|}
\hline & El estudiante... & Antes & Después \\
\hline 1. Destrezas relaciona & as con el pensamiento & & \\
\hline $\begin{array}{l}\text { 1.1. Creatividad e } \\
\text { innovación }\end{array}$ & Elabora o plantea hipótesis & 5 & 7 \\
\hline & $\begin{array}{c}\text { Utiliza nuevas ideas para solucionar } \\
\text { problemas }\end{array}$ & 3 & 5 \\
\hline & $\begin{array}{l}\text { Está interesado en las TIC como } \\
\text { herramientas para aprender mejor }\end{array}$ & 6 & 8 \\
\hline $\begin{array}{l}\text { 1.2. Pensamiento } \\
\text { crítico }\end{array}$ & Comprende los problemas planteados & 5 & 6 \\
\hline & Identifica causas y consecuencias & 4 & 6 \\
\hline & Busca soluciones a los problemas & 4 & 5 \\
\hline $\begin{array}{l}\text { 1.3. Aprender a } \\
\text { aprender }\end{array}$ & $\begin{array}{c}\text { Utiliza conceptos y herramientas de } \\
\text { diferentes materias para resolver problemas } \\
\text { geográficos }\end{array}$ & 3 & 5 \\
\hline & $\begin{array}{l}\text { Utiliza aprendizajes anteriores para } \\
\text { resolver problemas }\end{array}$ & 4 & 5 \\
\hline 2. Destrezas relaciona & as con "saber hacer" & & \\
\hline $\begin{array}{l}2.1 . \\
\text { Comunicación }\end{array}$ & $\begin{array}{l}\text { Usa diferentes formatos (textos, } \\
\text { expresión oral, imágenes, vídeos, etc.) para } \\
\text { comunicar }\end{array}$ & 5 & 7 \\
\hline & $\begin{array}{l}\text { Al comunicarse, utiliza una cantidad } \\
\text { suficiente de información }\end{array}$ & 4 & 6 \\
\hline & $\begin{array}{l}\text { Se comunica de forma lógicamente } \\
\text { ordenada }\end{array}$ & 4 & 4 \\
\hline & $\begin{array}{l}\text { Se comunica utilizando estrategias de } \\
\text { empatía }\end{array}$ & 2 & 4 \\
\hline 2.2. Colaboración & $\begin{array}{l}\text { Colabora con sus compañeros cuando } \\
\text { trabaja en equipo }\end{array}$ & 5 & 7 \\
\hline & $\begin{array}{c}\text { Evalúa críticamente sus } \\
\text { planteamientos y los de sus compañeros }\end{array}$ & 4 & 5 \\
\hline & Comprende su posición en el grupo & 3 & 6 \\
\hline 3. Destrezas en el ma & jo de herramientas de trabajo & & \\
\hline $\begin{array}{l}\text { 3.1. Manejo de la } \\
\text { información }\end{array}$ & $\begin{array}{l}\text { Puede identificar fuentes de } \\
\text { información }\end{array}$ & 3 & 5 \\
\hline & $\begin{array}{l}\text { Sabe seleccionar información objetiva } \\
\text { y relevante }\end{array}$ & 3 & 5 \\
\hline & $\begin{array}{l}\text { Sabe cómo tratar la información para } \\
\text { representar lo que desea }\end{array}$ & 3 & 5 \\
\hline & $\begin{array}{l}\text { Conoce diferentes formatos en los que } \\
\text { se puede presentar la información }\end{array}$ & 4 & 6 \\
\hline & $\begin{array}{l}\text { Evalúa las ventajas e inconvenientes } \\
\text { de los diferentes formatos en los que se } \\
\text { puede presentar la información }\end{array}$ & 3 & 4 \\
\hline
\end{tabular}


Velilla Gil, J., Guallart Moreno, C., Laguna Marín-Yaseli, M. (2021). Materiales educativos para trabajar conceptos sobre desarrollo sostenible en las aulas de educación secundaria. GeoFocus (Artículos), Revista Internacional de Ciencia y Tecnología de la Información Geográfica, 27, 55-93. http://dx.doi.org/10.21138/GF.676

\begin{tabular}{|c|c|c|c|}
\hline $\begin{array}{l}\text { 3.2. Destrezas } \\
\text { TIC }\end{array}$ & $\begin{array}{l}\text { Maneja con destreza editores de texto, } \\
\text { de imágenes y de vídeo, y hojas de cálculo }\end{array}$ & 6 & 6 \\
\hline & $\begin{array}{l}\text { Utiliza herramientas TIC para resolver } \\
\text { problemas }\end{array}$ & 5 & 7 \\
\hline & $\begin{array}{l}\text { Diferencia redes de comunicación de } \\
\text { fuentes de información }\end{array}$ & 3 & 5 \\
\hline \multicolumn{4}{|c|}{ 4. Destrezas ciudadanas } \\
\hline \multirow[t]{2}{*}{$\begin{array}{l}\text { 4.1. Vida y } \\
\text { estudios }\end{array}$} & Realiza las tareas encomendadas & 4 & 6 \\
\hline & Acepta sus errores e intenta corregirlos & 5 & 7 \\
\hline \multirow[t]{3}{*}{$\begin{array}{l}\text { 4.2. Personal y } \\
\text { social } \\
\text { responsabilidad }\end{array}$} & $\begin{array}{l}\text { Evalúa objetivamente los problemas } \\
\text { sociales y medioambientales planteados }\end{array}$ & 3 & 5 \\
\hline & $\begin{array}{l}\text { Plantea soluciones a los problemas } \\
\text { sociales y medioambientales planteados }\end{array}$ & 5 & 5 \\
\hline & $\begin{array}{l}\text { Se siente responsable de su } \\
\text { comportamiento }\end{array}$ & 4 & 6 \\
\hline
\end{tabular}

Fte.: Elaboración propia a partir de Binkley et al. (2012)

Tabla 2. Rúbrica evaluación alumnos con resultados inferiores a los esperados. Desarrollo de los procesos de aprendizaje

\begin{tabular}{|c|c|c|c|}
\hline & El estudiante... & Antes & Después \\
\hline 1. Destrezas relacion & as con el pensamiento & & \\
\hline $\begin{array}{l}\text { 1.1. Creatividad e } \\
\text { innovación }\end{array}$ & Elabora o plantea hipótesis & 2 & 4 \\
\hline & $\begin{array}{l}\text { Utiliza nuevas ideas para solucionar } \\
\text { problemas }\end{array}$ & 2 & 4 \\
\hline & $\begin{array}{l}\text { Está interesado en las TIC como } \\
\text { herramientas para aprender mejor }\end{array}$ & 5 & 6 \\
\hline $\begin{array}{l}\text { 1.2. Pensamiento } \\
\text { crítico }\end{array}$ & Comprende los problemas planteados & 3 & 5 \\
\hline & Identifica causas y consecuencias & 2 & 4 \\
\hline & Busca soluciones a los problemas & 4 & 5 \\
\hline $\begin{array}{l}\text { 1.3. Aprender a } \\
\text { aprender }\end{array}$ & $\begin{array}{c}\text { Utiliza conceptos y herramientas de } \\
\text { diferentes materias para resolver problemas } \\
\text { geográficos }\end{array}$ & 2 & 3 \\
\hline & $\begin{array}{l}\text { Utiliza aprendizajes anteriores para } \\
\text { resolver problemas }\end{array}$ & 2 & 4 \\
\hline 2. Destrezas relacion: & as con "saber hacer" & & \\
\hline $\begin{array}{l}2.1 . \\
\text { Comunicación }\end{array}$ & $\begin{array}{l}\text { Usa diferentes formatos (textos, } \\
\text { expresión oral, imágenes, vídeos, etc.) para } \\
\text { comunicar }\end{array}$ & 5 & 6 \\
\hline & $\begin{array}{l}\text { Al comunicarse, utiliza una cantidad } \\
\text { suficiente de información }\end{array}$ & 2 & 4 \\
\hline
\end{tabular}


Velilla Gil, J., Guallart Moreno, C., Laguna Marín-Yaseli, M. (2021). Materiales educativos para trabajar conceptos sobre desarrollo sostenible en las aulas de educación secundaria. GeoFocus (Artículos), Revista Internacional de Ciencia y Tecnología de la Información Geográfica, 27, 55-93. http://dx.doi.org/10.21138/GF.676

\begin{tabular}{|c|c|c|c|}
\hline & $\begin{array}{l}\text { Se comunica de forma lógicamente } \\
\text { ordenada }\end{array}$ & 2 & 3 \\
\hline & $\begin{array}{l}\text { Se comunica utilizando estrategias de } \\
\text { empatía }\end{array}$ & 3 & 4 \\
\hline \multirow[t]{3}{*}{ 2.2. Colaboración } & $\begin{array}{l}\text { Colabora con sus compañeros cuando } \\
\text { trabaja en equipo }\end{array}$ & 4 & 5 \\
\hline & $\begin{array}{l}\text { Evalúa críticamente sus } \\
\text { planteamientos y los de sus compañeros }\end{array}$ & 2 & 3 \\
\hline & Comprende su posición en el grupo & 2 & 3 \\
\hline \multicolumn{4}{|c|}{ 3. Destrezas en el manejo de herramientas de trabajo } \\
\hline \multirow[t]{5}{*}{$\begin{array}{l}\text { 3.1. Manejo de la } \\
\text { información }\end{array}$} & $\begin{array}{l}\text { Puede identificar fuentes de } \\
\text { información }\end{array}$ & 2 & 4 \\
\hline & $\begin{array}{l}\text { Sabe seleccionar información objetiva } \\
\text { y relevante }\end{array}$ & 3 & 4 \\
\hline & $\begin{array}{l}\text { Sabe cómo tratar la información para } \\
\text { representar lo que desea }\end{array}$ & 3 & 5 \\
\hline & $\begin{array}{l}\text { Conoce diferentes formatos en los que } \\
\text { se puede presentar la información }\end{array}$ & 4 & 5 \\
\hline & $\begin{array}{l}\text { Evalúa las ventajas e inconvenientes } \\
\text { de los diferentes formatos en los que se } \\
\text { puede presentar la información }\end{array}$ & 1 & 3 \\
\hline \multirow[t]{3}{*}{$\begin{array}{l}\text { 3.2. Destrezas } \\
\text { TIC }\end{array}$} & $\begin{array}{l}\text { Maneja con destreza editores de texto, } \\
\text { de imágenes y de vídeo, y hojas de cálculo }\end{array}$ & 4 & 5 \\
\hline & $\begin{array}{l}\text { Utiliza herramientas TIC para resolver } \\
\text { problemas }\end{array}$ & 4 & 6 \\
\hline & $\begin{array}{l}\text { Diferencia redes de comunicación de } \\
\text { fuentes de información }\end{array}$ & 2 & 4 \\
\hline \multicolumn{4}{|l|}{ 4. Destrezas ciudadanas } \\
\hline \multirow[t]{2}{*}{$\begin{array}{l}\text { 4.1. Vida y } \\
\text { estudios }\end{array}$} & Realiza las tareas encomendadas & 1 & 5 \\
\hline & Acepta sus errores e intenta corregirlos & 3 & 5 \\
\hline \multirow[t]{3}{*}{$\begin{array}{l}\text { 4.2. Personal y } \\
\text { social } \\
\text { responsabilidad }\end{array}$} & $\begin{array}{l}\text { Evalúa objetivamente los problemas } \\
\text { sociales y medioambientales planteados }\end{array}$ & 3 & 4 \\
\hline & $\begin{array}{l}\text { Plantea soluciones a los problemas } \\
\text { sociales y medioambientales planteados }\end{array}$ & 2 & 4 \\
\hline & $\begin{array}{l}\text { Se siente responsable de su } \\
\text { comportamiento }\end{array}$ & 4 & 5 \\
\hline
\end{tabular}

Fte.: Elaboración propia a partir de Binkley et al. (2012) 
